\title{
Doubly Nonlinear Parabolic Systems In Inhomogeneous Musielak- Orlicz-Sobolev Spcaes
}

\author{
Ahmed Aberqi $]^{\text {1 }}$, Mhamed Elmassoudi ${ }^{2}$, Jaouad Bennouna ${ }^{2}$, Mohamed Hammoumi ${ }^{2}$ \\ ${ }^{1}$ University of Fez, National school of applied sciences.Department of Electric and computer engineering, \\ $\mathrm{Fez}$, Morocco \\ ${ }^{2}$ University of Fez, Faculty of Sciences Dhar El Mahraz. Laboratory LAMA, Department of Mathematics, \\ B.P 1796 Atlas Fez, Morocco
}

A R T I C L E I N F O

Article history:

Received: 01 June, 2017

Accepted: 12 July, 2017

Online: 29 December, 2017

Keywords:

Parabolic system

Museilack-Orlicz spaces

Renormalized solutions

\begin{abstract}
A B S T R A C T
In this paper, we discuss the solvability of the nonlinear parabolic systems associated to the nonlinear parabolic equation: $\frac{\partial b_{i}\left(x, u_{i}\right)}{\partial t}-$ $\left.\operatorname{div}\left(a\left(x, t, u_{i}, \nabla u_{i}\right)\right)-\phi_{i}\left(x, t, u_{i}\right)\right)+f_{i}\left(x, u_{1}, u_{2}\right)=0$, where the function $b_{i}\left(x, u_{i}\right)$ verifies some regularity conditions, the term $\left(a\left(x, t, u_{i}, \nabla u_{i}\right)\right)$ is a generalized Leray-Lions operator and $\phi_{i}$ is a Caratheodory function assumed to be continuous on $u_{i}$ and satisfy only a growth condition. The source term $f_{i}\left(t, u_{1}, u_{2}\right)$ belongs to $L^{1}(\Omega \times(0, T))$.
\end{abstract}

\section{Introduction}

Given a bounded-connected open set $\Omega$ of $\mathbb{R}^{N}(N=2)$, with Lipschitz boundary $\partial \Omega, Q_{T}=\Omega \times(0, T)$ is the generic cylinder of an arbitrary finite hight, $T<+\infty$. We prove the existence of a renormalized solutions for the nonlinear parabolic systems:

$$
\begin{gathered}
\frac{\partial b_{i}\left(x, u_{i}\right)}{\partial t}-\operatorname{div}\left(a\left(x, t, u_{i}, \nabla u_{i}\right)\right)-\operatorname{div}\left(\Phi_{i}\left(x, t, u_{i}\right)\right) \\
+f_{i}\left(x, u_{1}, u_{2}\right)=0 \quad \text { in } Q_{T}, \\
u_{i}=0 \quad \text { on }(0, T) \times \partial \Omega, \\
b_{i}\left(x, u_{i}\right)(t=0)=b_{i}\left(x, u_{i, 0}\right) \quad \text { in } \Omega,
\end{gathered}
$$

where $\mathrm{i}=1,2$. Here the vector field $a: \Omega \times \mathbb{R} \times$ $\mathbb{R}^{N} \rightarrow \mathbb{R}^{N}$ is a Carathéodory function such that $-\operatorname{div}\left(a\left(x, t, u_{i}, \nabla u_{i}\right)\right)$ is a Leray-lions operator defined from the Inhomogeneous Musielak-Orlicz-Sobolev Spcaes $W_{0}^{1, x} L_{\varphi}\left(Q_{T}\right)$ into its dual $W^{-1, x} L_{\psi}\left(Q_{T}\right)$. Let $b_{i}$ : $\Omega \times \mathbb{R} \rightarrow \mathbb{R}$ a Carathéodory function such that for every $x \in \Omega, b_{i}(x,$.$) is a strictly increasing C^{1}$-function, the divegential term $\Phi_{i}\left(x, t, u_{i}\right)$ is a Carathéodory function satisfy only a polynomial growth with respect to the anisotropic $\mathrm{N}$-function $\varphi$ (see (4.6)), the data $u_{0, i}$ is in $L^{1}(\Omega)$ such that $b_{i}\left(., u_{0, i}\right)$ in $L^{1}(\Omega)$ and the source $f_{i}$ is a Carathéodory function satisfy the assumptions (4.7)(4.10)). When problem (1.1) is investigated, there is a difficulty due to the fact that the data $b_{1}\left(x, u_{0}^{1}(x)\right)$

\footnotetext{
${ }^{*}$ Corresponding Author: A. Aberqi, aberqi_ahmed@yahoo.fr
}

and $b_{2}\left(x, u_{0}^{2}(x)\right)$ only belong to $L^{1}$ and the functions $a\left(x, t, u_{i}, \nabla u_{i}\right), \Phi_{i}\left(x, t, u_{i}\right)$ and $f_{i}\left(x, u_{1}, u_{2}\right)$ do not belong to $\left(L_{l o c}^{1}\left(Q_{T}\right)\right)^{N}$ in general, so that proving existence of weak solution seems to be an arduous task, and we cannot use the Stocks formula in the a priori estimates of the nonlinearity , $\Phi_{i}\left(x, t, u_{i}\right)$. In order to overcome this difficulty, we work with the framework of renormalized solutions (see Definition 3.1). One of the models of applications of these operators is the system of Boussinesq:

$$
\begin{gathered}
\left.\frac{\partial u}{\partial t}+(u . \nabla)\right) u-2 \operatorname{div}(\mu(\theta) \varepsilon(u))+\nabla p=F(\theta) \quad \text { in } Q_{T} \\
\frac{\partial b(\theta)}{\partial t}+u \cdot \nabla b(\theta)-\Delta \theta=2 \mu(\theta)|\varepsilon(u)|^{2} \quad \text { in } Q_{T} \\
u(t=0)=u_{0}, b(\theta)(t=0)=b\left(\theta_{0}\right) \quad \text { on } \Omega \\
u=0 \quad \theta=0 \quad \text { on } \partial \Omega \times(0, T)
\end{gathered}
$$

Equation first equation is the motion conservation equation, the unknowns are the fields of displacement $u: Q_{T} \rightarrow \mathbb{R}^{N}$ and temperature $\theta: Q_{T} \rightarrow \mathbb{R}$, The field $\varepsilon(u)=\frac{1}{2}\left(\nabla u+(\nabla u)^{t}\right)$ is the strain rate tensor.

It is our purpose, in this paper to generalize the result of ([1], [2], [3]) and we prove the existence of a renormalized solution of system (1.1).

The plan of the paper is as follows: In Section 2 we give the framework space, in Section 3 and 4 we 
give some useful Lemmas and basics assumptions. In Section 5 we give the definition of a renormalized solution of $(1.1)$, and we establish (Theorem 5.1) the existence of such a solution.

\section{Preliminaries}

\subsection{Musielak-Orlicz function}

Let $\Omega$ be an open subset of $\mathbb{R}^{N}(N \geq 2)$, and let $\varphi$ be a real-valued function defined in $\Omega \times \mathbb{R}_{+}$and satisfying conditions:

$\Phi_{1}: \varphi(x,$.$) is an \mathrm{N}$-function for all $x \in \Omega$ (i.e. convex, non-decreasing, continuous, $\varphi(x, 0)=0$ ,$\varphi(x, 0)>0$ for $t>0, \lim _{t \rightarrow 0} \sup _{x \in \Omega} \frac{\varphi(x, t)}{t}=0$ and $\left.\lim _{t \rightarrow \infty} \inf _{x \in \Omega} \frac{\varphi(x, t)}{t}=\infty\right)$.

$\Phi_{2}: \varphi(., t)$ is a measurable function for all $t \geq 0$.

A function $\varphi$ which satisfies the conditions $\Phi_{1}$ and $\Phi_{2}$ is called a Musielak-Orlicz function.

For a Musielak-Orlicz function $\varphi$ we put $\varphi_{x}(t)=$ $\varphi(x, t)$ and we associate its non-negative reciprocal function $\varphi_{x}^{-1}$, with respect to $t$, that is

$$
\varphi_{x}^{-1}(\varphi(x, t))=\varphi\left(x, \varphi_{x}^{-1}(t)\right)=t
$$

Let $\varphi$ and $\gamma$ be two Musielak-Orlicz functions, we say that $\varphi$ dominate $\gamma$, and we write $\gamma<\varphi$, near infinity (resp.globally) if there exist two positive constants $c$ and $t_{0}$ such that for a.e. $x \in \Omega$

$\gamma(x, t) \leq \varphi(x, c t)$ for all $t \geq t_{0}$ (resp. for all $\left.t \geq 0\right)$. We say that $\gamma$ grows essentially less rapidly than $\varphi$ at 0 (resp. near infinity) and we write $\gamma \prec \prec \varphi$, for every positive constant $c$, we have

$\lim _{t \rightarrow 0}\left(\sup _{x \in \Omega} \frac{\gamma(x, c t)}{\varphi(x, t)}\right)=0$

$\left(\operatorname{resp} . \lim _{t \rightarrow \infty}\left(\sup _{x \in \Omega} \frac{\gamma(x, c t)}{\varphi(x, t)}\right)=0\right)$

Remark 2.1 [4]. If $\gamma \prec<\varphi$ near infinity, then $\forall \epsilon>0$ there exist $k(\epsilon)>0$ such that for almost all $x \in \Omega$, we have

$$
\gamma(x, t) \leq k(\epsilon) \varphi(x, \epsilon t) \quad \forall t \geq 0
$$

\subsection{Musielak-Orlicz space}

For a Musielak-Orlicz function $\varphi$ and a measurable function $u: \Omega \rightarrow \mathbb{R}$, we define the functionnal

$$
\rho_{\varphi, \Omega}(u)=\int_{\Omega} \varphi(x,|u(x)|) d x .
$$

The set $K_{\varphi}(\Omega)=\{u: \Omega \rightarrow \mathbb{R}$ mesurable : $\left.\rho_{\varphi, \Omega}(u)<\infty\right\}$ is called the Musielak-Orlicz class . The Musielak-Orlicz space $L_{\varphi}(\Omega)$ is the vector space generated by $K_{\varphi}(\Omega)$; that is, $L_{\varphi}(\Omega)$ is the smallest linear space containing the set $K_{\varphi}(\Omega)$. Equivalently
Young with respect to $s$. We say that a sequence of function $u_{n} \in L_{\varphi}(\Omega)$ is modular convergent to $u \in L_{\varphi}(\Omega)$ if there exists a constant $\lambda>0$ such that $\lim _{n \rightarrow \infty} \rho_{\varphi, \Omega}\left(\frac{u_{n}-u}{\lambda}\right)=0$

This implies convergence for $\sigma\left(\Pi L_{\varphi}, \Pi L_{\psi}\right)$ [see [5]].

In the space $L_{\varphi}(\Omega)$, we define the following two norms

$$
\|u\|_{\varphi}=\inf \left\{\lambda>0: \int_{\Omega} \varphi\left(x, \frac{|u(x)|}{\lambda}\right) d x \leq 1\right\}
$$

which is called the Luxemburg norm, and the socalled Orlicz norm by

$$
\left\|\left|u \|_{\varphi, \Omega}=\sup _{\|v\|_{\psi} \leq 1} \int_{\Omega}\right| u(x) v(x) \mid d x\right.
$$

where $\psi$ is the Musielak-Orlicz function complementary to $\varphi$. These two norms are equivalent [8]. $K_{\varphi}(\Omega)$ is a convex subset of $L_{\varphi}(\Omega)$. The closure in $L_{\varphi}(\Omega)$ of the set of bounded measurable functions with compact support in $\bar{\Omega}$ is by denoted $E_{\varphi}(\Omega)$. It is a separable space and $\left(E_{\varphi}(\Omega)\right)^{*}=L_{\varphi}(\Omega)$. We have $E_{\varphi}(\Omega)=K_{\varphi}(\Omega)$, if and only if $\varphi$ satisfies the $\Delta_{2}$-condition for large values of $t$ or for all values of $t$, according to whether $\Omega$ has finite measure or not.

We define

$$
\begin{array}{ll}
W^{1} L_{\varphi}(\Omega)=\left\{u \in L_{\varphi}(\Omega): D^{\alpha} u \in L_{\varphi}(\Omega),\right. & \forall \alpha \leq 1\} \\
W^{1} E_{\varphi}(\Omega)=\left\{u \in E_{\varphi}(\Omega): D^{\alpha} u \in E_{\varphi}(\Omega),\right. & \forall \alpha \leq 1\}
\end{array}
$$

where $\alpha=\left(\alpha_{1}, \ldots, \alpha_{N}\right),|\alpha|=\left|\alpha_{1}\right|+\ldots+\left|\alpha_{N}\right|$ and $: D^{\alpha} u$ denote the distributional derivatives. The space $W^{1} L_{\varphi}(\Omega)$ is called the Musielak-Orlicz-Sobolev space. Let

$\bar{\rho}_{\varphi, \Omega}(u)=\sum_{|\alpha| \leq 1} \rho_{\varphi, \Omega}\left(D^{\alpha} u\right)$ and $\|u\|_{\varphi, \Omega}^{1}=\inf \{\lambda>0$ : $\left.\bar{\rho}_{\varphi, \Omega}\left(\frac{u}{\lambda}\right) \leq 1\right\}$ for $u \in W^{1} L_{\varphi}(\Omega)$.

These functionals are convex modular and a norm on $W^{1} L_{\varphi}(\Omega)$, respectively. Then pair $\left(W^{1} L_{\varphi}(\Omega),\|u\|_{\varphi, \Omega}^{1}\right)$ is a Banach space if $\varphi$ satisfies the following condition [6].

There exists a constant $c>0$ such that $\inf _{x \in \Omega} \varphi(x, 1)>c$

The space $W^{1} L_{\varphi}(\Omega)$ is identified to a subspace of the product $\prod_{\alpha \leq 1} L_{\varphi}(\Omega)=\prod L_{\varphi}$ We denote by $\mathcal{D}(\Omega)$ the Schwartz space of infinitely smooth functions with compact support in $\Omega$ and by $\mathcal{D}(\bar{\Omega})$ the restriction of $\mathcal{D}(\mathbb{R})$ on $\Omega$. The space $W_{0}^{1} L_{\varphi}(\Omega)$ is defined as the $\sigma\left(\Pi L_{\varphi}, \Pi E_{\psi}\right)$ closure of $\mathcal{D}(\Omega)$ in $W^{1} L_{\varphi}(\Omega)$ and the space $W_{0}^{1} E_{\varphi}(\Omega)$ as the(norm) closure of the Schwartz space $\mathcal{D}(\Omega)$ in $W^{1} L_{\varphi}(\Omega)$. $\quad$ For two complementary Musielak-Orlicz functions $\varphi$ and $\psi$, we have (See [7]).

- The Young inequality: $L_{\varphi}(\Omega)=\left\{u: \Omega \rightarrow \mathbb{R}\right.$ mesurable : $\rho_{\varphi, \Omega}\left(\frac{u}{\lambda}\right)<\infty, \quad$ for some $\left.\lambda>s \hbar\right\} \varphi(x, s)+\psi(x, t)$ for all $s, t \geq 0, x \in \Omega$.

For any Musielak-Orlicz function $\varphi$, we put $\psi(x, s)=\sup _{t \geq 0}(s t-\varphi(x, s))$.

$\psi$ is called the Musielak-Orlicz function complementary to $\varphi$ (or conjugate of $\varphi$ ) in the sense of
- The Hölder inequality

$$
\begin{gathered}
\left|\int_{\Omega} u(x) v(x) d x\right| \leq\|u\|_{\varphi, \Omega}\|v \mid\|_{\psi, \Omega} \text { for all } \\
u \in L_{\varphi}(\Omega), v \in L_{\psi}(\Omega)
\end{gathered}
$$


We say that a sequence of functions $u_{n}$ converges to $u$ for the modular convergence in $W^{1} L_{\varphi}(\Omega)$ (respectively in $\left.W_{0}^{1} L_{\varphi}(\Omega)\right)$ if, for some $\lambda>0$.

$$
\lim _{n \rightarrow \infty} \bar{\rho}_{\varphi, \Omega}\left(\frac{u_{n}-u}{\lambda}\right)=0
$$

The following spaces of distributions will also be used

$$
\begin{aligned}
W^{-1} L_{\psi}(\Omega)= & \left\{f \in \mathcal{D}^{\prime}(\Omega): f=\sum_{\alpha \leq 1}(-1)^{\alpha} D^{\alpha} f_{\alpha}\right. \\
& \text { where } \left.f_{\alpha} \in L_{\psi}(\Omega)\right\}
\end{aligned}
$$

and

$$
\begin{gathered}
W^{-1} E_{\psi}(\Omega)=\left\{f \in \mathcal{D}^{\prime}(\Omega): f=\sum_{\alpha \leq 1}(-1)^{\alpha} D^{\alpha} f_{\alpha}\right. \\
\text { where } \left.f_{\alpha} \in E_{\psi}(\Omega)\right\}
\end{gathered}
$$

\subsection{Inhomogeneous Musielak-Orlicz- Sobolev spcaes:}

Let $\Omega$ be a bounded Lipschitz domain in $\mathbb{R}^{N}$ and let $Q=\Omega \times] 0, T[$ with some given $T>0$. let $\varphi$ be a Musielak-Orlicz function.For each $\alpha \in$

$N^{N}$, denote by $D_{x}^{\alpha}$ the distributional derivative on $Q_{T}$ of order $\alpha$ with respect to the variable $x \in$

$R^{N}$. The inhomogeneous Musielak-Orlicz-Sovolev spaces of order 1 are defined as follows

$$
\begin{aligned}
& W^{1, x} L_{\varphi}(Q)=\left\{u \in L_{\varphi}(Q): \forall|\alpha| \leq 1, \quad D_{x}^{\alpha} u \in L_{\varphi}(Q)\right\} \\
& W^{1, x} E_{\varphi}(Q)=\left\{u \in E_{\varphi}(Q): \forall|\alpha| \leq 1, \quad D_{x}^{\alpha} u \in E_{\varphi}(Q)\right\}
\end{aligned}
$$

The last is a subspace of the first one, and both are Banach spaces under the norm

$$
\|u\|=\sum_{|\alpha| \leq m}\left\|D_{x}^{\alpha} u\right\|_{\varphi, Q}
$$

We can easily show that they form a complementary system when $\Omega$ is a Lipschitz domain. These spaces are considered as subspaces of the product space $\Pi L_{\varphi}(Q)$ which has $(N+1)$ copies. We shall also consider the weak topologies $\sigma\left(\Pi L_{\varphi}, \Pi E_{\psi}\right)$ and $\sigma\left(\Pi L_{\varphi}, \Pi L_{\psi}\right)$. If $u \in W^{1, x} L_{\varphi}(Q)$ then the function : $t \mapsto u(t)=u(t,$.$) is defined on (0, T)$ with values in $W^{1} L_{\varphi}(\Omega)$. If, further, $u \in W^{1, x} E_{\varphi}(Q)$ then this function is a $W^{1} E_{\varphi}(\Omega)$-valued and is strongly measurable. Furthermore the following imbedding holds: $W^{1, x} E_{\varphi}(Q) \subset L^{1}\left(0, T ; W^{1} E_{\varphi}(\Omega)\right)$. The space $W^{1, x} L_{\varphi}(Q)$ is not in general separable, if $u \in$ $W^{1, x} L_{\varphi}(Q)$, we can not conclude that the function $u(t)$ is measurable on $(0, T)$. However, the scalar function $t \mapsto u(t)=\|u(t)\|_{\varphi, \Omega}$ is in $L^{1}(0, T)$. The space $W_{0}^{1, x} E_{\varphi}(Q)$ is defined as the (norm) closure in $W^{1, x} E_{\varphi}(Q)$ of $\mathcal{D}(\Omega)$. We can easily show that when $\Omega$ is a Lipschitz domain then each element $u$ of the closure of $\mathcal{D}(\Omega)$ with respect of the weak ${ }^{*}$ topology
$\sigma\left(\Pi L_{\varphi}, \Pi E_{\psi}\right)$ is limit, in $W^{1, x} L_{\varphi}(Q)$, of some subsequence $\left(u_{i}\right) \in \mathcal{D}(\Omega)$ for the modular convergence, i.e. there exists $\lambda>0$ such that for all $|\alpha| \leq 1$,

$$
\int_{Q} \varphi\left(x,\left(\frac{D_{x}^{\alpha} u_{i}-D_{x}^{\alpha} u}{\lambda}\right) d x d t \rightarrow 0 \quad \text { as } \quad i \rightarrow \infty\right.
$$

, this implies that $\left(u_{i}\right)$ converge to $u$ in $W^{1, x} L_{\varphi}(Q)$ for the weak topology $\sigma\left(\Pi L_{\varphi}, \Pi L_{\psi}\right)$. Consequently

$$
\mathcal{D}(Q)^{\sigma\left(\Pi L_{\varphi}, \Pi E_{\psi}\right)}=\mathcal{D}(Q)^{\sigma\left(\Pi L_{\varphi}, \Pi L_{\psi}\right)}
$$

, this space will be denoted by $W_{0}^{1, x} L_{\varphi}(Q)$. Furthermore $W_{0}^{1, x} E_{\varphi}(Q)=W_{0}^{1, x} L_{\varphi}(Q) \cap \Pi E_{\varphi}$. We have the following complementary system $F$ being the dual space of $W_{0}^{1, x} E_{\varphi}(Q)$. It is also, except for an isomorphism, the quotient of $\Pi L_{\psi}$ by the polar set $W_{0}^{1, x} E_{\varphi}(Q)^{\perp}$, and will be denoted by $F=W^{1, x} L_{\psi}(Q)$ and it is shown that

this space will be equipped with the usual quotient norm

where the inf is taken on all possible decompositions

The space $F_{0}$ is then given by $F_{0}=W^{-1, x} E_{\psi}(Q)$.

Lemma 2.1 [4]. Let $\Omega$ be a bounded Lipschitz domain in $\mathbb{R}^{N}$ and let $\varphi$ and $\psi$ be two complementary MusielakOrlicz functions which satisfy the following conditions:

- There exists a constant $c>0$ such that

$$
\inf _{x \in \Omega} \varphi(x, 1)>c
$$

- $\exists A>0$ such that for all $x, y \in \Omega$ with $|x-y| \leq \frac{1}{2}$, we have

$$
\begin{gathered}
\frac{\varphi(x, t)}{\varphi(y, t)} \leq t^{\left(\frac{A}{\log \left(\frac{1}{|x-y|}\right)}\right)} \text { for all } t \geq 1 \\
\int_{\Omega} \varphi(y, 1) d x<\infty
\end{gathered}
$$

$\exists C>0$ such that $\psi(y, t) \leq C \quad$ a.e. in $\Omega$

Under this assumptions $\mathcal{D}(\Omega)$ is dense in $L_{\varphi}(\Omega)$ with respect to the modular topology, $\mathcal{D}(\Omega)$ is dense in $W_{0}^{1} L_{\varphi}(\Omega)$ for the modular convergence and $\mathcal{D}(\bar{\Omega})$ is dense in $W_{0}^{1} L_{\varphi}(\Omega)$ for the modular convergence.

Consequently, the action of a distribution $S$ in $W^{-1} L \psi(\Omega)$ on an element $u$ of $W_{0}^{1} L_{\varphi}(\Omega)$ is well defined. It will be denoted by $<S, u>$. 


\subsection{Truncation Operator}

$T_{k}, k>0$, denotes the truncation function at level $k$ defined on $\mathbb{R}$ by $T_{k}(r)=\max (-k, \min (k, r))$. The following abstract lemmas will be applied to the truncation operators.

Lemma 2.2 [4]. Let $F: \mathbb{R} \rightarrow \mathbb{R}$ be uniformly Lipschitzian, with $F(0)=0$. Let $\varphi$ be an Musielak-Orlicz function and let $u \in W_{0}^{1} L_{\varphi}(\Omega)\left(\right.$ resp. $\left.u \in W^{1} E_{\varphi}(\Omega)\right)$. Then $F(u) \in W^{1} L_{\varphi}(\Omega)$ (resp.u $\left.\in W_{0}^{1} E_{\varphi}(\Omega)\right)$.Moreover, if the set of discontinuity points $D$ of $F^{\prime}$ is finite, then

$$
\frac{\partial}{\partial x_{i}} F(u)= \begin{cases}F^{\prime}(x) \frac{\partial u}{\partial x_{i}} & \text { a.e. in }\{x \in \Omega ; u(x) \notin D\} \\ 0 & \text { a.e. in }\{x \in \Omega ; u(x) \in D\}\end{cases}
$$

Lemma 2.3 Suppose that $\Omega$ satisfies the segment property and let $u \in W_{0}^{1} L_{\varphi}(\Omega)$. Then, there exists a sequence $u_{n} \in \mathcal{D}(\Omega)$ such that

$$
u_{n} \rightarrow u \text { for modular convergence in } W_{0}^{1} L_{\varphi}(\Omega) .
$$

Furthermore, if $u \in W_{0}^{1} L_{\varphi}(\Omega) \cap L^{\infty}(\Omega)$ then $\left\|u_{n}\right\|_{\infty} \leq$ $(N+1)\|u\|_{\infty}$.

Let $\Omega$ be an open subset of $\mathbb{R}^{N}$ and let $\varphi$ be a Musielak-Orlicz function satisfying :

$$
\int_{0}^{1} \frac{\varphi_{x}^{-1}(t)}{t^{\frac{N+1}{N}}} d t=\infty \quad \text { a.e. } \quad x \in \Omega
$$

and the conditions of Lemma 2.1. We may assume without loss of generality that

$$
\int_{0}^{1} \frac{\varphi_{x}^{-1}(t)}{t^{\frac{N+1}{N}}} d t<\infty \quad \text { a.e. } x \in \Omega
$$

Define a function $\varphi^{*}: \Omega \times[0, \infty)$ by $\varphi^{*}(x, s)=$ $\int_{0}^{s} \frac{\varphi_{x}^{-1}(t)}{t \frac{N+1}{N}} d t x \in \Omega$ and $s \in[0, \infty)$.

$\varphi^{*}$ its called the Sobolev conjugate function of $\varphi$ (see [1] for the case of Orlicz function).

Theorem 2.1 Let $\Omega$ be a bounded Lipschitz domain and let $\varphi$ be a Musielak-Orlicz function satisfying 2.5.2.6 and the conditions of Lemma 2.1. Then

$$
W_{0}^{1} L_{\varphi}(\Omega) \hookrightarrow L_{\varphi^{*}}(\Omega)
$$

where $\varphi^{*}$ is the Sobolev conjugate function of $\varphi$. Moreover, if $\phi$ is any Musielak-Orlicz function increasing essentially more slowly than $\varphi^{*}$ near infinity, then the imbedding

$$
W_{0}^{1} L_{\varphi}(\Omega) \hookrightarrow L_{\phi}(\Omega)
$$

is compact

Corollary 2.1 Under the same assumptions of theorem 5.1. we have

$$
W_{0}^{1} L_{\varphi}(\Omega) \hookrightarrow \hookrightarrow L_{\varphi}(\Omega)
$$

Lemma 2.4 If a sequence un $u_{n} \in L_{\varphi}(\Omega)$ converges a.e. to $u$ and if $u_{n}$ remains bounded in $L_{\varphi}(\Omega)$, then $u \in L_{\varphi}(\Omega)$ and $u_{n} \rightarrow u$ for $\sigma\left(L_{\varphi}(\Omega), E_{\psi}(\Omega)\right)$.
Lemma 2.5 Let $u_{n}, u \in L_{\varphi}(\Omega)$. If $u_{n} \rightarrow u$ with respect to the modular convergence, then $u_{n} \rightarrow u$ for $\sigma\left(L_{\varphi}(\Omega), L_{\psi}(\Omega)\right)$.

See $([8])$.

\section{Technical lemma}

Lemma 3.1 Under the assumptions of lemma 2.1. and by assuming that $\varphi(x, t)$ decreases with respect to one of coordinate of $x$, there exists a constant $c_{1}>0$ which depends only on $\Omega$ such that

$$
\int_{\Omega} \varphi(x,|u|) d x \leq \int_{\Omega} \varphi\left(x, c_{1}|\nabla u|\right) d x
$$

Theorem 3.1 Let $\Omega$ be a bounded Lipschitz domain and let $\varphi$ be a Musielak-Orlicz function satisfying the same conditions of Theorem 5.1 Then there exists a constant $\lambda>0$ such that

$$
\|u\|_{\varphi} \leq \lambda\|\nabla u\|_{\varphi}, \quad \forall \in W_{0}^{1} L_{\varphi}(\Omega)
$$

\section{Essential assumptions}

Let $\Omega$ be an open subset of $\mathbb{R}^{N}(N \geq 2)$ satisfying the segment property,and let $\varphi$ and $\gamma$ be two MusielakOrlicz functions such that $\varphi$ and its complementary $\psi$ satisfies conditions of Lemma 2.1 and $\gamma<<\varphi$.

$$
b_{i}: \Omega \times \mathbb{R} \rightarrow \mathbb{R}
$$

is a Carathéodory function such that for every $x \in \Omega$,

$b_{i}(x,$.$) is a strictly increasing \mathcal{C}^{1}(\mathbb{R})$-function and $b_{i} \in$ $L^{\infty}(\Omega \times \mathbb{R})$ with $b_{i}(x, 0)=0$. Next for any $k>0$, there exists a constant $\lambda_{k}^{i}>0$ and functions $A_{k}^{i} \in L^{\infty}(\Omega)$ and $B_{k}^{i} \in L_{\varphi}(\Omega)$ such that:

$$
\begin{gathered}
\lambda_{k}^{i} \leq \frac{\partial b_{i}(x, s)}{\partial s} \leq A_{k}^{i}(x) \text { and }\left|\nabla_{x}\left(\frac{\partial b_{i}(x, s)}{\partial s}\right)\right| \leq B_{k}^{i}(x) \\
\text { a.e. } x \in \Omega \text { and } \forall|s| \leq k .
\end{gathered}
$$

$A: D(A) \subset W_{0}^{1} L_{\varphi}\left(Q_{T}\right) \rightarrow W^{-1} L_{\psi}\left(Q_{T}\right)$ defined by $A(u)=-\operatorname{div} a(x, t, u, \nabla u)$, where $a: Q \times \mathbb{R} \times \mathbb{R}^{N} \rightarrow \mathbb{R}^{N}$ is Carathéodory function such that for a.e. $x \in \Omega$ and for all $s \in \mathbb{R}, \xi, \xi^{*} \in \mathbb{R}^{N}, \xi \neq \xi^{*}$

$\left(A_{1}\right):|a(x, t, s, \xi)| \leq \beta\left(c(x)+\psi_{x}^{-1}\left(\gamma\left(x, v_{1}|s|\right)\right)+\right.$ $\left.\psi_{x}^{-1}\left(\varphi\left(x, v_{2}|\xi|\right)\right)\right)$,

$$
\begin{gathered}
\beta>0, \quad c(x) \in E_{\psi}(\Omega), \\
\left(A_{2}\right):\left(a(x, t, s, \xi)-a\left(x, s, \xi^{*}\right)\left(\xi-\xi^{*}\right)>0,\right. \\
\left(A_{3}\right): a(x, t, s, \xi) . \xi \geq \alpha \varphi(x,|\xi|) .
\end{gathered}
$$

$\Phi(x, s, \xi): \Omega \times I R \times I R^{N} \rightarrow I R^{N}$ is a Carathéodory function such that

$$
\left|\Phi_{i}(x, t, s)\right| \leq \psi_{x}^{-1} \varphi(x,|s|),
$$

$f_{i}: \Omega \times \mathbb{R} \times \mathbb{R} \rightarrow \mathbb{R}$ is a Carathéodory function with $f_{1}(x, 0, s)=f_{2}(x, s, 0)=0 \quad$ a.e. $x \in \Omega, \forall s \in \mathbb{R}$. 
and for almost every $x \in \Omega$, for every $s_{1}, s_{2} \in \mathbb{R}$,

$$
\operatorname{sign}\left(s_{i}\right) f_{i}\left(x, s_{1}, s_{2}\right) \geq 0 \text {. }
$$

The growth assumptions on $f_{i}$ are as follows: For each $K>0$, there exists $\sigma_{K}>0$ and a function $F_{K}$ in $L^{1}(\Omega)$ such that

$$
\left|f_{1}\left(x, s_{1}, s_{2}\right)\right| \leq F_{K}(x)+\sigma_{K}\left|b_{2}\left(x, s_{2}\right)\right|
$$

a.e. in $\Omega$, for all $s_{1}$ such that $\left|s_{1}\right| \leq K$, for all $s_{2} \in \mathbb{R}$. For each $K>0$, there exists $\lambda_{K}>0$ and a function $G_{K}$ in $L^{1}(\Omega)$ such that

$$
\left|f_{2}\left(x, s_{1}, s_{2}\right)\right| \leq G_{K}(x)+\lambda_{K}\left|b_{1}\left(x, s_{1}\right)\right|,
$$

for almost every $x \in \Omega$, for every $s_{2}$ such that $\left|s_{2}\right| \leq K$, and for every $s_{1} \in \mathbb{R}$.

Finally, we assume the following condition on the initial data $u_{i, 0}$ : for $\mathrm{i}=1,2$.

$u_{i, 0}$ is a measurable function such that $b_{i}\left(., u_{i, 0}\right) \in L^{1}(\Omega)$,

In this paper, for $K>0$, we denote by $T_{K}: r \mapsto$ $\min (K, \max (r,-K))$ the truncation function at height $K$. For any measurable subset $E$ of $Q_{T}$, we denote by meas $(E)$ the Lebesgue measure of $E$. For any measurable function $v$ defined on $Q$ and for any real number $s, \chi_{\{v<s\}}$ (respectively, $\chi_{\{v=s\}}, \chi_{\{v>s\}}$ ) denote the characteristic function of the set $\left\{(x, t) \in Q_{T} ; v(x, t)<s\right\}$ (respectively, $\left\{(x, t) \in Q_{T} ; v(x, t)=s\right\},\left\{(x, t) \in Q_{T} ; v(x, t)>\right.$ $s\})$.

Definition 4.1 A couple of functions $\left(u_{1}, u_{2}\right)$ defined on $Q$ is called a renormalized solution of 4.1-4.11) if for $i=1,2$ the function $u_{i}$ satisfies

$$
\begin{aligned}
& T_{K}\left(u_{i}\right) \in W_{0}^{1, x} L_{\varphi}\left(Q_{T}\right) \text { and } b_{i}\left(x, u_{i}\right) \in L^{\infty}\left(0, T ; L^{1}(\Omega)\right), \\
& \int_{\left\{m \leq\left|u_{i}\right| \leq m+1\right\}} a\left(x, t, u_{i}, \nabla u_{i}\right) \nabla u_{i} d x d t \rightarrow 0 \text { as } m \rightarrow+\infty,
\end{aligned}
$$

For every function $S$ in $W^{2, \infty}(\mathbb{R})$ which is piecewise $C^{1}$ and such that $S^{\prime}$ has a compact support, we have

$$
\begin{gathered}
\frac{\partial B_{i, S}\left(x, u_{i}\right)}{\partial t}-\operatorname{div}\left(S^{\prime}\left(u_{i}\right) a\left(x, t, u_{i}, \nabla u_{i}\right)\right) \\
+S^{\prime \prime}\left(u_{i}\right) a\left(x, t, u_{i}, \nabla u_{i}\right) \nabla u_{i} \\
+\operatorname{div}\left(S^{\prime}\left(u_{i}\right) \phi_{i}\left(x, t, u_{i}\right)\right)-S^{\prime \prime}\left(u_{i}\right) \phi_{i}\left(x, t, u_{i}\right) \nabla u_{i} \\
+f_{i}\left(x, u_{1}, u_{2}\right) S^{\prime}\left(u_{i}\right)=0, \\
B_{i, S}\left(x, u_{i}\right)(t=0)=B_{i, S}\left(x, u_{i, 0}\right) \quad \text { in } \Omega,
\end{gathered}
$$

where $B_{i, S}(r)=\int_{0}^{r} b_{i}^{\prime}(x, s) S^{\prime}(s) d s$.

Due to 4.12, each term in 4.14 has a meaning in $W^{-1, x} L_{\psi}\left(Q_{T}\right)+L^{1}\left(Q_{T}\right)$.

Indeed, if $K$ such that suppS $\subset[-K, K]$, the following identifications are made in 4.14
- $B_{i, S}\left(x, u_{i}\right) \in L^{\infty}\left(Q_{T}\right)$, since $\left|B_{i, S}\left(x, u_{i}\right)\right| \leq$ $K\left\|A_{K}^{i}\right\|_{L^{\infty}(\Omega)}\left\|S^{\prime}\right\|_{L^{\infty}(\mathbb{R})}$

- $S^{\prime}\left(u_{i}\right) a\left(x, t, u_{i}, \nabla u_{i}\right)$ can be identified with $S^{\prime}\left(u_{i}\right) a\left(x, t, T_{K}\left(u_{i}\right), \nabla T_{K}\left(u_{i}\right)\right)$ a.e. in $Q_{T}$. Since indeed $\left|T_{K}\left(u_{i}\right)\right| \leq K$ a.e. in $Q_{T}$, . As a consequence of $4.3,4.12$ and $S^{\prime}\left(u_{i}\right) \in L^{\infty}\left(Q_{T}\right)$, it follows that

$$
S^{\prime}\left(u_{i}\right) a\left(x, T_{K}\left(u_{i}\right), \nabla T_{K}\left(u_{i}\right)\right) \in\left(L_{\psi}\left(Q_{T}\right)\right)^{N} .
$$

- $S^{\prime}\left(u_{i}\right) a\left(x, t, u_{i}, \nabla u_{i}\right) \nabla u_{i}$ can be identified with $S^{\prime}\left(u_{i}\right) a\left(x, t, T_{K}\left(u_{i}\right), \nabla T_{K}\left(u_{i}\right)\right) \nabla T_{K}\left(u_{i}\right)$ a.e. $\quad$ in $Q_{T}$.with 4.2 and 4.12 it has

$$
S^{\prime}\left(u_{i}\right) a\left(x, t, T_{K}\left(u_{i}\right), \nabla T_{K}\left(u_{i}\right)\right) \nabla T_{K}\left(u_{i}\right) \in L^{1}\left(Q_{T}\right)
$$

- $S^{\prime}\left(u_{i}\right) \Phi_{i}\left(u_{i}\right)$ and $S^{\prime \prime}\left(u_{i}\right) \Phi_{i}\left(u_{i}\right) \nabla u_{i} \quad$ respectively identify with $S^{\prime}\left(u_{i}\right) \Phi_{i}\left(T_{K}\left(u_{i}\right)\right)$ and $S^{\prime \prime}\left(u_{i}\right) \Phi\left(T_{K}\left(u_{i}\right)\right) \nabla T_{K}\left(u_{i}\right)$. In view of the properties of $S$ and 4.6 , the functions $S^{\prime}, S^{\prime \prime}$ and $\Phi \circ T_{K}$ are bounded on $\mathbb{R}$ so that 4.12 implies that $S^{\prime}\left(u_{i}\right) \Phi_{i}\left(T_{K}\left(u_{i}\right)\right) \in\left(L^{\infty}\left(Q_{T}\right)\right)^{N}$ and $S^{\prime \prime}\left(u_{i}\right) \Phi_{i}\left(T_{K}\left(u_{i}\right)\right) \nabla T_{K}\left(u_{i}\right) \in\left(L_{\psi}\left(Q_{T}\right)\right)^{N}$.

- $S^{\prime}\left(u_{i}\right) f_{i}\left(x, u_{1}, u_{2}\right)$ identifies with $S^{\prime}\left(u_{i}\right) f_{1}\left(x, T_{K}\left(u_{1}\right), u_{2}\right)$ a.e. in $Q_{T}$ (or $S^{\prime}\left(u_{i}\right) f_{2}\left(x, u_{1}, T_{K}\left(u_{2}\right)\right)$ a.e. in $\left.Q_{T}\right)$. Indeed, since $\left|T_{K}\left(u_{i}\right)\right| \leq K$ a.e. in $Q_{T}$, assumptions 4.9 and 4.10 and using 4.12 and of $S^{\prime}\left(u_{i}\right) \in L^{\infty}(Q)$, one has

$$
\begin{aligned}
& S^{\prime}\left(u_{1}\right) f_{1}\left(x, T_{K}\left(u_{1}\right), u_{2}\right) \in L^{1}\left(Q_{T}\right) \\
& \text { and } S^{\prime}\left(u_{2}\right) f_{2}\left(x, u_{1}, T_{K}\left(u_{2}\right)\right) \in L^{1}\left(Q_{T}\right) .
\end{aligned}
$$

As consequence, (4.14) takes place in $D^{\prime}\left(Q_{T}\right)$ and that

$$
\frac{\partial B_{i, S}\left(x, u_{i}\right)}{\partial t} \in W^{-1, x} L_{\psi}\left(Q_{T}\right)+L^{1}\left(Q_{T}\right) .
$$

Due to the properties of $S$ and 4.2

$$
B_{i, S}\left(x, u_{i}\right) \in W_{0}^{1, x} L_{\varphi}\left(Q_{T}\right) .
$$

Moreover 4.16 and 4.17 implies that $B_{i, S}\left(x, u_{i}\right) \in C^{0}\left([0, T], L^{1}(\Omega)\right)$ so that the initial condition 4.15 makes sense.

\section{Existence result}

We shall prove the following existence theorem

Theorem 5.1 Assume that 4.1-4.11 hold true. There at least a renormalized solution $\left(u_{1}, u_{2}\right)$ of Problem (1.1).

We divide the prof in 5 steps.

Step 1: Approximate problem.

Let us introduce the following regularization of the data: for $n>0$ and $i=1,2$

$$
b_{i, n}(x, s)=b_{i}\left(x, T_{n}(s)\right)+\frac{1}{n} s \quad \forall s \in \mathbb{R},
$$

$a_{n}(x, t, s, \xi)=a\left(x, t, T_{n}(s), \xi\right)$ a.e. in $\Omega, \forall s \in \mathbb{R}, \forall \xi \in \mathbb{R}^{N}$, 
$\Phi_{i, n}(x, t, s)=\Phi_{i, n}\left(x, t, T_{n}(s)\right) \quad$ a.e. $\quad(x, t) \in Q_{T}, \quad \forall s \in I R$

$$
\begin{array}{ll}
f_{1, n}\left(x, s_{1}, s_{2}\right)=f_{1}\left(x, T_{n}\left(s_{1}\right), s_{2}\right) & \text { a.e. in } \Omega, \forall s_{1}, s_{2} \in \underset{R}{(5.4}, \\
f_{2, n}\left(x, s_{1}, s_{2}\right)=f_{2}\left(x, s_{1}, T_{n}\left(s_{2}\right)\right) & \text { a.e. in } \Omega, \forall s_{1}, s_{2} \in \mathbb{R},
\end{array}
$$

$u_{i, 0 n} \in C_{0}^{\infty}(\Omega), b_{i, n}\left(x, u_{i, 0 n}\right) \rightarrow b_{i}\left(x, u_{i, 0}\right) \quad \operatorname{in} L^{1}(\Omega)$

$$
\text { as } n \text { tends to }+\infty
$$

Let us now consider the regularized problem $\frac{\partial b_{i, n}\left(x, u_{i, n}\right)}{\partial t}-\operatorname{div}\left(a_{n}\left(x, u_{i, n}, \nabla u_{i, n}\right)\right)-\operatorname{div}\left(\Phi_{i, n}\left(x, t, u_{i, n}\right)\right)$

$$
\begin{gathered}
+f_{i, n}\left(x, u_{1, n}, u_{2, n}\right)=0 \quad \text { in } Q_{T}, \\
u_{i, n}=0 \quad \text { on }(0, T) \times \partial \Omega, \\
b_{i, n}\left(x, u_{i, n}\right)(t=0)=b_{i, n}\left(x, u_{i, 0 n}\right) \quad \text { in } \Omega .
\end{gathered}
$$

In view of 5.1 , for $i=1,2$, we have

$$
\frac{\partial b_{i, n}(x, s)}{\partial s} \geq \frac{1}{n}, \quad\left|b_{i, n}(x, s)\right| \leq \max _{|s| \leq n}\left|b_{i}(x, s)\right|+1 \quad \forall s \in \mathbb{R},
$$

In view of 4.9)-(4.10, $f_{1, n}$ and $f_{2, n}$ satisfy: There exists $F_{n} \in L^{1}(\Omega), G_{n} \in L^{1}(\Omega)$ and $\sigma_{n}>0, \lambda_{n}>0$, such that

$$
\left|f_{1, n}\left(x, s_{1}, s_{2}\right)\right| \leq F_{n}(x)+\sigma_{n} \max _{|s| \leq n}\left|b_{i}(x, s)\right|
$$

a.e. in $x \in \Omega, \forall s_{1}, s_{2} \in \mathbb{R}$,

$$
\left|f_{2, n}\left(x, s_{1}, s_{2}\right)\right| \leq G_{n}(x)+\lambda_{n} \max _{|s| \leq n}\left|b_{i}(x, s)\right|
$$

a.e. in $x \in \Omega, \forall s_{1}, s_{2} \in \mathbb{R}$. As a consequence, proving the existence of a weak solution $u_{i, n} \in W_{0}^{1, x} L_{\varphi}\left(Q_{T}\right)$ of 5.7-5.9 is an easy task (see e.g. [9]).

\section{Step2:A priori estimates.}

Let $t \in(0, T)$ and using $T_{k}\left(u_{i, n}\right) \chi_{(0, t)}$ as a test function in problem 5.7), we get: $\int_{\Omega} B_{i, k}^{n}\left(x, u_{i, n}(t)\right) d x+\int_{Q_{t}} a_{n}\left(x, t, u_{i, n}, \nabla u_{i, n}\right) \nabla T_{k}\left(u_{i, n}\right) d x d t$

$$
\begin{aligned}
& +\int_{Q_{t}} \phi_{i, n}\left(x, t, u_{i, n}\right) \nabla T_{k}\left(u_{i, n}\right) d x d t \\
& +\int_{Q_{t}} f_{i, n} T_{k}\left(u_{i, n}\right) d x d t \leq \int_{\Omega} B_{i, k}^{n}\left(x, u_{i, 0 n}\right) d x,
\end{aligned}
$$

where $B_{i, k}^{n}(x, r)=\int_{0}^{r} \frac{\partial b_{i, n}(x, s)}{\partial s} T_{k}(s) d s$.

Due to definition of $B_{i, k}^{n}$ we have:

$$
\int_{\Omega} B_{i, k}^{n}\left(x, u_{i, n}(t)\right) d x \geq \frac{\lambda_{n}}{2} \int_{\Omega}\left|T_{k}\left(u_{i, n}\right)\right|^{2} d x, \quad \forall k>0,
$$

and

$$
\begin{gathered}
0 \leq \int_{\Omega} B_{i, k}^{n}\left(x, u_{i, 0 n}\right) d x \leq k \int_{\Omega}\left|b_{i, n}\left(x, u_{i, 0 n}\right)\right| d x \\
\leq k\left\|b_{i}\left(x, u_{i, 0}\right)\right\|_{L^{1}(\Omega)}, \quad \forall k>0 .
\end{gathered}
$$

In view of 4.8, we have $\int_{Q_{t}} f_{i, n} T_{k}\left(u_{i, n}\right) d x d t \geq 0$ Also, we obtain with Young inequality:

$$
\int_{Q_{t}} \phi_{i, n}\left(x, t, u_{i, n}\right) \nabla T_{k}\left(u_{i, n}\right) d x d t
$$

$$
\begin{aligned}
= & \int_{\left\{\left|u_{i, n}\right| \leq k\right\}} \phi_{i, n}\left(x, t, u_{i, n}\right) \nabla T_{k}\left(u_{i, n}\right) d x d t \\
\leq & \int_{\left\{\left|u_{i, n}\right| \leq k\right\}} \psi\left(x, \frac{1}{\alpha_{0}^{i}} \phi_{i, n}\left(x, t, u_{i, n}\right)\right) d x d t \\
& +\int_{\left\{\left|u_{i, n}\right| \leq k\right\}} \varphi\left(x, \alpha_{0}^{i} \nabla T_{k}\left(u_{i, n}\right)\right) d x d t \\
\leq & \int_{\left\{\left|u_{i, n}\right| \leq k\right\}} \psi\left(x, \frac{1}{\alpha_{0}^{i}} \psi_{x}^{-1} \varphi(x,|k|)\right) d x d t \\
& +\int_{\left\{\left|u_{i, n}\right| \leq k\right\}} \varphi\left(x, \alpha_{0}^{i} \nabla T_{k}\left(u_{i, n}\right) d x d t\right. \\
\leq & \int_{\left\{\left|u_{i, n}\right| \leq k\right\}} \psi\left(x, \frac{1}{\alpha_{0}^{i}} \psi_{x}^{-1} \varphi(x,|k|)\right) d x d t \\
& +\int_{\left\{\left|u_{i, n}\right| \leq k\right\}} \varphi\left(x, \alpha_{0}^{i} \nabla T_{k}\left(u_{i, n}\right) d x d t\right.
\end{aligned}
$$

then

$$
\begin{aligned}
& \int_{Q_{t}} \phi_{i, n}\left(x, t, T_{k}\left(u_{i, n}\right)\right) \nabla T_{k}\left(u_{i, n}\right) d x d t \\
\leq & C_{i, k}+\alpha_{0}^{i} \int_{Q_{t}} \varphi\left(x, \nabla T_{k}\left(u_{i, n}\right)\right) d x d t
\end{aligned}
$$

We conclude that

$$
\frac{\lambda}{2} \int_{\Omega}\left|T_{k}\left(u_{i, n}\right)\right|^{2} d x+\alpha^{i} \int_{Q_{t}} \varphi\left(x, \nabla T_{k}\left(u_{i, n}\right) d x d t\right.
$$

$\leq \alpha_{0}^{i} \int_{Q_{t}} \varphi\left(x, \nabla T_{k}\left(u_{i, n}\right)\right) d t d x+C_{i, k}+k\left\|b_{i}\left(x, u_{i, 0 n}\right)\right\|_{L^{1}(\Omega)}$

Then

$\frac{\lambda}{2} \int_{\Omega}\left|T_{k}\left(u_{i, n}\right)\right|^{2} d x+\left(\alpha^{i}-\alpha_{0}^{i}\right) \int_{Q_{t}} \varphi\left(x, \nabla T_{k}\left(u_{i, n}\right)\right) d t d x \leq C_{i} \cdot k$

Choosing $\alpha_{0}^{i}$ such that

$$
0<\alpha_{0}^{i}<\min \left(1, \alpha^{i}\right)
$$

we get

$$
\int_{Q_{t}} \varphi\left(x, \nabla T_{k}\left(u_{i, n}\right)\right) d x d t \leq C_{i} \cdot k
$$

Then, by (5.14), we conclude that $T_{k}\left(u_{i, n}\right)$ is bounded in $W^{1, x} L_{\varphi}\left(Q_{T}\right)$ independently of $n$ and for any $k \geq 0$, so there exists a subsequence still denoted by $u_{n}$ such that

$$
T_{k}\left(u_{i, n}\right) \rightarrow \psi_{i, k}
$$

weakly in $W_{0}^{1, x} L_{\varphi}\left(Q_{T}\right)$ for $\sigma\left(\Pi L_{\varphi}, \Pi E_{\psi}\right)$ strongly in $E_{\varphi}\left(Q_{T}\right)$ and a.e in $Q_{T}$.

Since Lemma 3.1 and 5.14, we get also,

$$
\varphi(x, k) \operatorname{meas}\left\{\left\{\left|u_{i, n}\right|>k\right\} \cap B_{R} \times[0, T]\right\}
$$

$\leq \int_{0}^{T} \int_{\left\{\left|u_{i, n}\right|>k\right\} \cap B_{R}} \varphi\left(x, T_{k}\left(u_{i, n}\right)\right) d x d t$

$\leq \int_{Q_{T}} \varphi\left(x, T_{k}\left(u_{i, n}\right)\right) d x d t$ 
$\leq \operatorname{diam} Q_{T} \int_{Q_{T}} \varphi\left(x, \nabla T_{k}\left(u_{i, n}\right)\right) d x d t$

Then

$$
\operatorname{meas}\left\{\left\{\left|u_{i, n}\right|>k\right\} \cap B_{R} \times[0, T]\right\} \leq \frac{\operatorname{diam} Q_{T} \cdot C_{i} \cdot k}{\varphi(x, k)}
$$

Which implies that:

$$
\lim _{k \rightarrow+\infty} \operatorname{meas}\left\{\left\{\left|u_{i, n}\right|>k\right\} \cap B_{R} \times[0, T]\right\}=0 . \text { uniformly }
$$

with respect to $n$.

Now we turn to prove the almost every convergence of $u_{i, n}, b_{i, n}\left(x, u_{i, n}\right)$ and convergence of $a_{i, n}\left(x, t, T_{k}\left(u_{i, n}\right), \nabla T_{k}\left(u_{i, n}\right)\right)$.

Proposition 5.1 Let $u_{i, n}$ be a solution of the approximate problem, then:

$$
\begin{array}{r}
u_{i, n} \rightarrow u_{i} \quad \text { a.e in } \quad Q_{T} . \\
b_{i, n}\left(x, u_{i, n}\right) \rightarrow b_{i}\left(x, u_{i}\right) \quad \text { a.e in } \quad Q_{T} \\
b_{i}\left(x, u_{i}\right) \in L^{\infty}\left(0, T, L^{1}(\Omega)\right) . \\
a_{n}\left(x, t, T_{k}\left(u_{i, n}\right), \nabla T_{k}\left(u_{i, n}\right)\right) \rightarrow X_{i, k} \\
\text { in }\left(L_{\psi}\left(Q_{T}\right)\right)^{N} \text { for } \sigma\left(\Pi L_{\psi}, \Pi E_{\varphi}\right)
\end{array}
$$

for some $X_{i, k} \in\left(L_{\psi}\left(Q_{T}\right)\right)^{N}$

$\lim _{m \rightarrow+\infty} \lim _{n \rightarrow+\infty} \int_{m \leq\left|u_{i, n}\right| \leq m+1} a_{i}\left(x, t, u_{i, n}, \nabla u_{i, n}\right) \nabla u_{i, n} d x d t=0$

Proof of 5.16 and 5.17:

Consider now a function non decreasing $g_{k} \in C^{2}(I R)$ such that $g_{k}(s)=s$ for $|s| \leq \frac{k}{2}$ and $g_{k}(s)=k$ for $|s| \geq k$. Multiplying the approximate equation by $g_{k}^{\prime}\left(u_{i, n}\right)$, we get

$$
\begin{gathered}
\frac{\partial B_{k, g}^{i, n}\left(x, u_{i, n}\right)}{\partial t}-\operatorname{div}\left(a_{n}\left(x, t, u_{i, n}, \nabla u_{i, n}\right) g_{k}^{\prime}\left(u_{i, n}\right)\right) \\
+a_{n}\left(x, t, u_{i, n}, \nabla u_{i, n}\right) g_{k}^{\prime \prime}\left(u_{i, n}\right) \nabla u_{i, n} \\
+\operatorname{div}\left(\phi_{i, n}\left(x, t, u_{i, n}\right) g_{k}^{\prime}\left(u_{i, n}\right)\right)-g_{k}^{\prime \prime}\left(u_{i, n}\right) \phi_{i, n}\left(x, t, u_{i, n}\right) \nabla u_{i, n} \\
+f_{i, n} g_{k}^{\prime}\left(u_{n}\right)=0 \quad \text { in } D^{\prime}\left(Q_{T}\right)
\end{gathered}
$$

where $B_{k, g}^{i, n}(x, z)=\int_{0}^{z} \frac{\partial b_{i, n}(x, s)}{\partial s} g_{k}^{\prime}(s) d s$.

Using 5.20, we can deduce that $g_{k}\left(u_{i, n}\right)$ is bounded in $W_{0}^{1, x} L_{\varphi}\left(Q_{T}\right)$ and $\frac{\partial B_{k, g}^{i, n}\left(x, u_{i, n}\right)}{\partial t}$ is bounded in $L^{1}\left(Q_{T}\right)+$ $W^{-1, x} L_{\psi}\left(Q_{T}\right)$ independently of $n$.

thanks to 4.6 and properties of $g_{k}$, it follows that

$$
\begin{gathered}
\left|\int_{Q_{T}} \phi_{i, n}\left(x, t, u_{n}\right) g_{k}^{\prime}\left(u_{i, n}\right) d x d t\right| \\
\leq\left\|g_{k}^{\prime}\right\|_{\infty} \int_{Q_{T}} c_{i}(x, t) \psi^{-1} \varphi\left(x, T_{k}\left(u_{i, n}\right)\right) d x d t
\end{gathered}
$$

$$
\left.\leq\left\|g_{k}^{\prime}\right\|_{\infty}\left(\psi^{-1} \varphi(x, k)\right) \int_{Q_{T}} c_{i}(x, t) d x d t\right) \leq C_{i, k}^{1}
$$

By 5.13, we get

$$
\left|\int_{Q_{T}} g_{k}^{\prime \prime}\left(u_{i, n}\right) \phi_{i, n}\left(x, t, u_{i, n}\right) \nabla u_{i, n} d x d t\right|
$$

$$
\leq\left\|g_{k}^{\prime}\right\|_{\infty}\left(C_{i, k}+c_{0}^{i} \int_{Q_{T}} \psi\left(x, \nabla T_{k}\left(u_{i, n}\right)\right) d x d t\right) \leq C_{i, k}^{2}
$$

where $C_{i, k}^{1}$ and $C_{i, k}^{2}$ constants independently of $n$. we conclude that $\frac{\partial g_{k}\left(u_{i, n}\right)}{\partial t}$ is bounded in $L^{1}\left(Q_{T}\right)+$ $W^{-1, x} L_{\psi}\left(Q_{T}\right)$ for $k<n$. which implies that $g_{k}\left(u_{i, n}\right)$ is compact in $L^{1}\left(Q_{T}\right)$. Due to the choice of $g_{k}$, we conclude that for each $k$, the sequence $T_{k}\left(u_{i, n}\right)$ converges almost everywhere in $Q_{T}$, which implies that the sequence $u_{i, n}$ converge almost everywhere to some measurable function $u_{i}$ in $Q_{T}$.

Then by the same argument in [9], we have

$$
u_{i, n} \rightarrow u_{i} \text { a.e. } Q_{T} \text {, }
$$

where $u_{i}$ is a measurable function defined on $Q_{T}$. and

$$
b_{i, n}\left(x, u_{i, n}\right) \rightarrow b_{i}\left(x, u_{i}\right) \quad \text { a.e. in } \quad Q_{T}
$$

by 5.15 and 5.21 we have

$$
T_{k}\left(u_{i, n}\right) \rightarrow T_{k}\left(u_{i}\right)
$$

weakly in $W_{0}^{1, x} L_{\varphi}\left(Q_{T}\right)$ for $\sigma\left(\Pi L_{\varphi}, \Pi E_{\psi}\right)$ strongly in $E_{\varphi}\left(Q_{T}\right)$ and a.e in $Q_{T}$.

We now show that $b_{i}\left(x, u_{i}\right) \in L^{\infty}\left(0, T ; L^{1}(\Omega)\right)$. Indeed using $\frac{1}{\varepsilon} T_{\varepsilon}\left(u_{i, n}\right)$ as a test function in (5.7),

$\frac{1}{\varepsilon} \int_{\Omega} b_{i, n}^{\varepsilon}\left(x, u_{i, n}\right)(t) d x+\frac{1}{\varepsilon} \int_{Q_{T}} a_{n}\left(x, u_{i, n}, \nabla u_{i, n}\right) \nabla T_{\varepsilon}\left(u_{i, n}\right) d x d t$ $-\frac{1}{\varepsilon} \int_{Q_{T}} \Phi_{i, n}\left(x, t, u_{i, n}\right) \nabla T_{\varepsilon}\left(u_{i, n}\right) d x d t+\frac{1}{\varepsilon} \int_{Q_{T}} f_{i, n}\left(x, u_{1, n}, u_{2, n}\right) T_{\varepsilon}\left(u_{i, n}\right)$ $=\frac{1}{\varepsilon} \int_{\Omega} b_{i, n}^{\varepsilon}\left(x, u_{i, 0 n}\right) d x$,

for almost any $t$ in $(0, T)$. Where, $b_{i, n}^{\varepsilon}(r)=$ $\int_{0}^{r} b_{i, n}^{\prime}(s) T_{\varepsilon}(s) d s$. Since $a_{n}$ satisfies 4.5 and $f_{i, n}$ satisfies 4.8 , we get

$$
\begin{gathered}
\int_{\Omega} b_{i, n}^{\varepsilon}\left(x, u_{i, n}\right)(t) d x \leq \int_{Q_{T}} \Phi_{i, n}\left(x, t, u_{i, n}\right) \nabla T_{\varepsilon}\left(u_{i, n}\right) d x d t \\
+\int_{\Omega} b_{i, n}^{\varepsilon}\left(x, u_{i, 0 n}\right) d x
\end{gathered}
$$

By Young inequality and 4.6, we get

$$
\begin{aligned}
& \int_{Q_{T}} \Phi_{i, n}\left(x, t, u_{i, n}\right) \nabla T_{\varepsilon}\left(u_{i, n}\right) d x d t \leq \int_{\left|u_{i, n}\right| \leq \varepsilon} \psi\left(x, \Phi_{i, n}\left(x, t, u_{i, n}\right)\right) d x d t \\
& \quad+\int_{\left|u_{i, n}\right| \leq \varepsilon} \varphi\left(x, \nabla T_{\varepsilon}\left(u_{i, n}\right)\right) d x d t \\
& \leq \varepsilon \psi\left(x, \frac{\alpha}{\lambda+1} \psi^{-1} \varphi(x, 1)\right) . \operatorname{meas}\left(Q_{T}\right)+\int_{\left|u_{i, n}\right| \leq \varepsilon}\left(\varphi\left(x, \nabla T_{\varepsilon}\left(u_{i, n}\right)\right) d x d t\right.
\end{aligned}
$$


Using the Lebesgue's Theorem and $\varphi\left(x, \nabla T_{\varepsilon}\left(u_{i, n}\right)\right) \in$ $W_{0}^{1, x} L\left(Q_{T}\right)$ in second term of the left hand side of the 5.25 and Letting $\varepsilon \rightarrow 0$ in 5.24) we obtain

$$
\int_{\Omega}\left|b_{i, n}\left(x, u_{i, n}\right)(t)\right| d x \leq\left\|b_{i, n}\left(x, u_{i, 0 n}\right)\right\|_{L^{1}(\Omega)}
$$

for almost $t \in(0, T)$. thanks to 5.6 , (5.16), and passing to the limit-inf in 5.26), we obtain $b_{i}\left(x, u_{i}\right) \in$ $L^{\infty}\left(0, T ; L^{1}(\Omega)\right)$. Proof of 5.18$)$ :

Following the same way in([10]), we deduce that $a_{n}\left(x, t, T_{k}\left(u_{i, n}\right), \nabla T_{k}\left(u_{i, n}\right)\right)$ is a bounded sequence in $\left(L_{\psi}\left(Q_{T}\right)\right)^{N}$, and we obtain 5.18.

Proof of 5.19):

Multiplying the approximating equation 5.7 by the test function $\theta_{m}\left(u_{i, n}\right)=T_{m+1}\left(u_{i, n}\right)-T_{m}\left(u_{i, n}\right)$

$$
\begin{aligned}
& \int_{\Omega} B_{i, m}\left(x, u_{i, n}(T)\right) d x+ \\
& \quad \int_{Q_{T}} a_{n}\left(x, t, u_{i, n}, \nabla u_{i, n}\right) \nabla \theta_{m}\left(u_{i, n}\right) d x d t \\
& \quad+\int_{Q_{T}} \phi_{i, n}\left(x, t, u_{i, n}\right) \nabla \theta_{m}\left(u_{i, n}\right) d x d t \\
& \quad+\int_{Q_{T}} f_{i, n} \theta_{m}\left(u_{i, n}\right) d x d t \leq \int_{\Omega} B_{i, m}\left(x, u_{i, 0 n}\right) d x
\end{aligned}
$$

where $B_{i, m}(x, r)=\int_{0}^{r} \theta_{m}(s) \frac{\partial b_{i, n}(x, s)}{\partial s} d s$.

By 4.6 , we have

$$
\begin{gathered}
\int_{Q_{T}} \phi_{i, n}\left(x, t, u_{i, n}\right) \nabla \theta_{m}\left(u_{i, n}\right) d x d t \\
\leq \int_{m \leq\left|u_{i, n}\right| \leq m+1} \psi\left(x, \frac{\beta}{\epsilon} \psi_{x}^{-1} \varphi\left(x,\left|u_{i, n}\right|\right)\right) d x d t \\
+\epsilon \int_{m \leq\left|u_{i, n}\right| \leq m+1} \varphi\left(x, \nabla \theta_{m}\left(u_{i, n}\right)\right) d x d t
\end{gathered}
$$

Also $\int_{Q_{T}} f_{i, n} \theta_{m}\left(u_{i, n}\right) d x d t \geq 0$ in view of 4.8.Then, The same argument in step 2 , we obtain,

$$
\begin{gathered}
\int_{Q_{T}} \varphi\left(x, \nabla u_{i, n}\right) d x d t \\
\leq C_{i}\left(\int_{m \leq\left|u_{i, n}\right| \leq m+1} \psi\left(x, \frac{\beta}{\epsilon} \psi^{-1} \varphi\left(x,\left|u_{i, n}\right|\right)\right) d x d t\right. \\
\left.+\int_{\Omega} B_{i, m}\left(x, u_{i, 0 n}\right) d x\right)
\end{gathered}
$$

Where $C_{i}=\frac{1}{\alpha^{i}-\epsilon}$ where $0<\epsilon<\alpha^{i}$.

passing to limit as $n \rightarrow+\infty$, since the pointwise convergence of $u_{i, n}$ and strongly convergence in $L^{1}\left(Q_{T}\right)$ of $B_{i, m}\left(x, u_{i, 0 n}\right)$ we get

$$
\begin{gathered}
\lim _{n \rightarrow+\infty} \int_{Q_{T}} \varphi\left(x, \nabla u_{i, n}\right) d x d t \\
\leq C_{i}\left(\int_{m \leq\left|u_{i}\right| \leq m+1} \psi\left(x, \frac{\beta}{\epsilon} \psi_{x}^{-1} \varphi\left(x,\left|u_{i}\right|\right)\right) d x d t\right.
\end{gathered}
$$

$$
\left.+\int_{\Omega} B_{i, m}\left(x, u_{i, 0}\right) d x\right)
$$

By using Lebesgue's theorem and passing to limit as $m \rightarrow+\infty$, in the all term of the right-hand side, we get

$$
\lim _{m \rightarrow+\infty} \lim _{n \rightarrow+\infty} \int_{m \leq\left|u_{i}\right| \leq m+1} \varphi\left(x, \nabla u_{i, n}\right) d x d t=0
$$

and the other hand, we have

$$
\begin{aligned}
& \lim _{m \rightarrow+\infty} \lim _{n \rightarrow+\infty} \int_{Q_{T}} \phi_{i, n}\left(x, t, u_{i, n}\right) \nabla \theta_{m}\left(u_{i, n}\right) d x d t \\
\leq & \lim _{m \rightarrow+\infty} \lim _{n \rightarrow+\infty} \int_{m \leq\left|u_{i}\right| \leq m+1} \varphi\left(x, \nabla \theta_{m}\left(u_{i, n}\right)\right) d x d t \\
+ & \lim _{m \rightarrow+\infty} \lim _{n \rightarrow+\infty} \int_{m \leq\left|u_{i, n}\right| \leq m+1} \psi\left(x, \phi_{i, n}\left(x, t, u_{i, n}\right)\right) d x d t
\end{aligned}
$$

Using the pointwise convergence of $u_{i, n}$ and by Lebesgue's theorem,in the second term of the right side, we get

$$
\begin{gathered}
\lim _{n \rightarrow+\infty} \int_{m \leq\left|u_{i, n}\right| \leq m+1} \psi\left(x, \phi_{i, n}\left(x, t, u_{i, n}\right)\right) d x d t \\
=\int_{m \leq\left|u_{i}\right| \leq m+1} \psi\left(x, \phi_{i}\left(x, t, u_{i}\right)\right) d x d t,
\end{gathered}
$$

and also ,by Lebesgue's theorem

$$
\lim _{m \rightarrow+\infty} \int_{m \leq\left|u_{i}\right| \leq m+1} \psi\left(x, \phi_{i}\left(x, t, u_{i}\right)\right) d x d t=0
$$

we obtain with 5.28 and 5.29,

$$
\lim _{m \rightarrow+\infty} \lim _{n \rightarrow+\infty} \int_{Q_{T}} \phi_{i, n}\left(x, t, u_{i, n}\right) \nabla \theta_{m}\left(u_{i, n}\right) d x d t=0
$$

then passing to the limit in 5.27), we get the 5.19). Step 3: Let $v_{i, j} \in \mathcal{D}\left(Q_{T}\right)$ be a sequence such that $v_{i, j} \rightarrow$ $u_{i}$ in $W_{0}^{1, x} L_{\varphi}\left(Q_{T}\right)$ for the modular convergence.

This specific time regularization of $T_{k}\left(v_{i, j}\right)$ (for fixed $k \geq 0)$ is defined as follows.

Let $\left(\alpha_{i, 0}^{\mu}\right)_{\mu}$ be a sequence of functions defined on $\Omega$ such that

$$
\begin{gathered}
\alpha_{i, 0}^{\mu} \in L^{\infty}(\Omega) \cap W_{0}^{1} L_{\varphi}(\Omega) \text { for all } \mu>0 \\
\left\|\alpha_{i, 0}^{\mu}\right\|_{L^{\infty}(\Omega)} \leq k \text { for all } \mu>0 .
\end{gathered}
$$

and $\alpha_{i, 0}^{\mu}$ converges to $T_{k}\left(u_{i, 0}\right)$ a.e. in $\Omega$ and $\frac{1}{\mu}\left\|\alpha_{i, 0}^{\mu}\right\|_{\varphi, \Omega}$ converges to $\quad 0 \quad \mu \rightarrow+\infty$.

For $k \geq 0$ and $\mu>0$, let us consider the unique solution $\left(T_{k}\left(v_{i, j}\right)\right)_{\mu} \in L^{\infty}(Q) \cap W_{0}^{1, x} L_{\varphi}\left(Q_{T}\right)$ of the monotone problem:

$$
\begin{gathered}
\frac{\partial\left(T_{k}\left(v_{i, j}\right)\right)_{\mu}}{\partial t}+\mu\left(\left(T_{k}\left(v_{i, j}\right)\right)_{\mu}-T_{k}\left(v_{i, j}\right)\right)=0 \text { in } D^{\prime}(\Omega), \\
\left(T_{k}\left(v_{i, j}\right)\right)_{\mu}(t=0)=\alpha_{i, 0}^{\mu} \text { in } \Omega .
\end{gathered}
$$

Remark that due to

$$
\frac{\partial\left(T_{k}\left(v_{i, j}\right)\right)_{\mu}}{\partial t} \in W_{0}^{1, x} L_{\varphi}\left(Q_{T}\right)
$$


We just recall that,

for fixed $K \geq 0$ :

$\liminf _{\mu \rightarrow+\infty} \lim _{j \rightarrow+\infty} \lim _{n \rightarrow+\infty} \int_{Q_{T}}\left\langle\frac{\partial b_{i, S_{m}}\left(u_{i, n}\right)}{\partial t}, S_{m}^{\prime}\left(u_{i, n}\right) W_{i, j, \mu}^{n}\right\rangle \geq 0$,

$\left(T_{k}\left(v_{i, j}\right)\right)_{\mu} \rightarrow T_{k}\left(u_{i}\right)$ a.e. in $Q_{T}$, weakly* in $L^{\infty}\left(Q_{T}\right)$,

$$
\lim _{\mu \rightarrow+\infty} \lim _{j \rightarrow+\infty} \lim _{n \rightarrow+\infty} \int_{Q_{T}} S_{n}^{\prime}\left(u_{i, n}\right) \Phi_{i, n}\left(x, t, u_{i, n}\right) \nabla W_{i, j, \mu}^{n}=0,
$$

$$
\left(T_{k}\left(v_{i, j}\right)\right)_{\mu} \rightarrow\left(T_{k}\left(u_{i}\right)\right)_{\mu} \quad \text { in } \quad W_{0}^{1, x} L_{\varphi}\left(Q_{T}\right)
$$

$\lim _{\mu \rightarrow+\infty} \lim _{j \rightarrow+\infty} \lim _{n \rightarrow+\infty} \int_{Q_{T}} S_{m}^{\prime \prime}\left(u_{i, n}\right) W_{i, \mu}^{n} \Phi_{i, n}\left(x, t, u_{i, n}\right) \nabla u_{i, n}=0$,

for the modular convergence as $j \rightarrow+\infty$.

$$
\left(T_{k}\left(u_{i}\right)\right)_{\mu} \rightarrow T_{k}\left(u_{i}\right) \quad \text { in } \quad W_{0}^{1, x} L_{\varphi}\left(Q_{T}\right)
$$

for the modular convergence as $\mu \rightarrow+\infty$.

$$
\lim _{m \rightarrow+\infty} \varlimsup_{\mu \rightarrow+\infty} \lim _{j \rightarrow+\infty} \overline{\lim _{n \rightarrow+\infty}}\left|\int_{Q_{T}} S_{m}^{\prime \prime}\left(u_{i, n}\right) W_{i, j, \mu}^{n} a_{n}\left(x, t, u_{i, n}, \nabla u_{i, n}\right) \nabla u_{i, n}\right|=0
$$

$$
\lim _{\mu \rightarrow+\infty} \lim _{j \rightarrow+\infty} \lim _{n \rightarrow+\infty} \int_{Q_{T}} f_{i, n}\left(x, u_{1, n}, u_{2, n}\right) S_{m}^{\prime}\left(u_{i, n}\right) W_{i, j, \mu}^{n}=0 .
$$

$\left\|\left(T_{k}\left(v_{i, j}\right)\right)_{\mu}\right\|_{L^{\infty}\left(Q_{T}\right)} \leq \max \left(\left\|\left(T_{k}\left(u_{i}\right)\right)\right\|_{L^{\infty}\left(Q_{T}\right)},\left\|\alpha_{0}^{\mu}\right\|_{L^{\infty}(\Omega)}\right) \leq k$

$$
\limsup _{n \rightarrow+\infty} \int_{Q_{T}} a\left(x, t, u_{i, n}, \nabla T_{K}\left(u_{i, n}\right)\right) \nabla T_{K}\left(u_{i, n}\right) d x d t
$$

$\forall \mu>0, \forall k>0$. Now, we introduce a sequence of increasing $C^{\infty}(\mathbb{R})$-functions $S_{m}$ such that, for any $m \geq 1$

$$
\leq \int_{Q_{T}} X_{i, K} \nabla T_{K}\left(u_{i}\right) d x d t
$$

$$
\begin{gathered}
\int_{Q_{T}}\left[a\left(x, t, T_{k}\left(u_{i, n}\right), \nabla T_{k}\left(u_{i, n}\right)\right)-a\left(x, t, T_{k}\left(u_{i, n}\right), \nabla T_{k}\left(u_{i}\right)\right)\right] \\
{\left[\nabla T_{k}\left(u_{i, n}\right)-\nabla T_{k}\left(u_{i}\right)\right] d x d t \rightarrow 0 .}
\end{gathered}
$$

$S_{m}(r)=r$ for $|r| \leq m, \quad \operatorname{supp}\left(S_{m}^{\prime}\right) \subset[-(m+1),(m+1)]$,

$$
\left\|S_{m}^{\prime \prime}\right\|_{L^{\infty}(\mathbb{R})} \leq 1 \text {. }
$$

(5.38) Proof of 5.41:

Through setting, for fixed $K \geq 0$,

\section{Lemma 5.1}

$$
\int_{Q_{T}}\left\langle\frac{\partial b_{i, n}\left(x, u_{i, n}\right)}{\partial t}, S_{m}^{\prime}\left(u_{i, n}\right) W_{i, j, \mu}^{n}\right\rangle d x d t \geq \epsilon(n, j, \mu, m),
$$

$W_{i, j, \mu}^{n}=T_{K}\left(u_{i, n}\right)-T_{K}\left(v_{i, j}\right)_{\mu} \quad$ and $\quad W_{i, \mu}^{n}=T_{K}\left(u_{i, n}\right)-T_{K}\left(u_{i}\right)_{\mu}$

we obtain upon integration,

$$
\begin{aligned}
& \int_{Q_{T}}\left\langle\frac{\partial b_{i, S_{m}}\left(u_{i, n}\right)}{\partial t}, W_{i, j, \mu}^{n}\right\rangle d x d t \\
& +\int_{Q_{T}} S_{m}^{\prime}\left(u_{i, n}\right) a_{n}\left(x, u_{i}^{n}, \nabla u_{i, n}\right) \nabla W_{i, j, \mu}^{n} d x d t \\
& +\int_{Q_{T}} S_{m}^{\prime \prime}\left(u_{i, n}\right) W_{i, j, \mu}^{n} a_{n}\left(x, u_{i, n}, \nabla u_{i, n}\right) \nabla u_{i, n} d x d t \\
& +\int_{Q_{T}} \Phi_{i, n}\left(x, t, u_{i, n}\right) S_{m}^{\prime}\left(u_{i, n}\right) \nabla W_{i, j, \mu}^{n} d x d t \\
& +\int_{Q_{T}} S_{m}^{\prime \prime}\left(u_{i, n}\right) W_{i, j, \mu}^{n} \Phi_{i, n}\left(x, t, u_{i, n}\right) \nabla u_{i, n} d x d t \\
& +\int_{Q_{T}} f_{i, n}\left(x, u_{1, n}, u_{2, n}\right) S_{m}^{\prime}\left(u_{i, n}\right) W_{i, j, \mu}^{n} d x d t=0
\end{aligned}
$$

Next we pass to the limit as $n$ tends to $+\infty, j$ tends to $+\infty, \mu$ tends to $+\infty$ and then $m$ tends to $+\infty$, the real number $K \geq 0$ being kept fixed. In order to perform this task we prove below the following results
See [23]. Proof of 5.42):

If we take $n>m+1$, we get

$$
\phi_{i, n}\left(x, t, u_{i, n}\right) S_{m}^{\prime}\left(u_{i, n}\right)=\phi_{i}\left(x, t, T_{m+1}\left(u_{i, n}\right)\right) S_{m}^{\prime}\left(u_{i, n}\right)
$$

Using 4.6, we have:

$$
\begin{gathered}
\psi\left(\phi_{i, n}\left(x, t, T_{m+1}\left(u_{i, n}\right) S_{m}^{\prime}\left(u_{i, n}\right)\right) \leq(m+1) \psi\left(\phi_{i}\left(x, t, T_{m+1}\left(u_{i, n}\right)\right)\right)\right. \\
\leq(m+1) \psi\left(\|c(x, t)\|_{L^{\infty}\left(Q_{T}\right)} \psi^{-1} M(m+1)\right)
\end{gathered}
$$

Then $\phi_{i, n}\left(x, t, u_{n}\right) S_{m}\left(u_{i, n}\right)$ is bounded in $L_{\psi}\left(Q_{T}\right)$, thus, by using the pointwise convergence of $u_{i, n}$ and Lebesgue's theorem we obtain $\phi_{i, n}\left(x, t, u_{i, n}\right) S_{m}\left(u_{i, n}\right) \rightarrow$ $\phi_{i}\left(x, t, u_{i}\right) S_{m}\left(u_{i}\right)$ with the modular convergence as $n \rightarrow+\infty$, then $\phi_{i, n}\left(x, t, u_{i, n}\right) S_{m}\left(u_{i, n}\right) \rightarrow \phi\left(x, t, u_{i}\right) S_{m}\left(u_{i}\right)$ for $\sigma\left(\prod L_{\psi}, \prod L_{\varphi}\right)$.

In the other hand $\nabla W_{i, j, \mu}^{n}=\nabla T_{k}\left(u_{i, n}\right)-\nabla\left(T_{k}\left(v_{i, j}\right)\right)_{\mu}$ for converge to $\nabla T_{k}\left(u_{i}\right)-\nabla\left(T_{k}\left(v_{i, j}\right)\right)_{\mu}$ weakly in $\left(L_{\varphi}\left(Q_{T}\right)\right)^{N}$,then

$$
\begin{aligned}
& \int_{Q_{T}} \phi_{i, n}\left(x, t, u_{i, n}\right) S_{m}\left(u_{i, n}\right) \nabla W_{i, j, \mu}^{n} d x d t \\
& \rightarrow \int_{Q_{T}} \phi_{i}\left(x, t, u_{i}\right) S_{m}\left(u_{i}\right) \nabla W_{i, j, \mu} d x d t
\end{aligned}
$$


as $n \rightarrow+\infty$.

By using the modular convergence of $W_{i, j, \mu}$ as $j \rightarrow+\infty$ and letting $\mu$ tends to infinity, we get 5.42 .

Proof of 5.43:

For $n>m+1>k$, we have $\nabla u_{i, n} S_{m}^{\prime \prime}\left(u_{i, n}\right)=\nabla T_{m+1}\left(u_{i, n}\right)$ a.e. in $Q_{T}$. By the almost every where convergence of $u_{i, n}$ we have $W_{i, j, \mu}^{n} \rightarrow W_{i, j, \mu}$ in $L^{\infty}\left(Q_{T}\right)$ weak${ }^{*}$ and since the sequence $\left(\phi_{i, n}\left(x, t, T_{m+1}\left(u_{i, n}\right)\right)\right)_{n}$ converge strongly in $E_{\psi}\left(Q_{T}\right)$ then

$$
\phi_{i, n}\left(x, t, T_{m+1}\left(u_{i, n}\right)\right) W_{i, j, \mu}^{n} \rightarrow \phi_{i}\left(x, t, T_{m+1}\left(u_{i}\right)\right) W_{i, j, \mu}
$$

converge strongly in $E_{\psi}\left(Q_{T}\right)$ as $n \rightarrow+\infty$. By virtue of $\nabla T_{m+1}\left(u_{n}\right) \rightarrow \nabla T_{m+1}\left(u_{i}\right)$ weakly in $\left(L_{\varphi}\left(Q_{T}\right)\right)^{N}$ as $n \rightarrow$ $+\infty$ we have

$$
\int_{m \leq\left|u_{i, n}\right| \leq m+1} \phi_{i, n}\left(x, t, T_{m+1}\left(u_{i, n}\right)\right) \nabla u_{i, n} S_{m}^{\prime \prime}\left(u_{i, n}\right) W_{i, j, \mu}^{n} d x d t
$$

$$
\left.\rightarrow \int_{m \leq\left|u_{i}\right| \leq m+1} \phi\left(x, t, u_{i}\right)\right) \nabla u_{i} W_{i, j, \mu} d x d t
$$

as $n \rightarrow+\infty$

with the modular convergence of $W_{i, j, \mu}$ as $j \rightarrow+\infty$ and letting $\mu \rightarrow+\infty$ we get (5.43).

Proof of 5.44:

For any $m \geq 1$ fixed, we have

$$
\begin{aligned}
& \left|\int_{Q_{T}} S_{m}^{\prime \prime}\left(u_{i, n}\right) a_{n}\left(x, t, u_{i, n}, \nabla u_{i, n}\right) \nabla u_{i, n} W_{i, j, \mu}^{n} d x d t\right| \\
& \leq\left\|S_{m}^{\prime \prime}\right\|_{L^{\infty}(\mathbb{R})}\left\|W_{i, j, \mu}^{n}\right\|_{L^{\infty}\left(Q_{T}\right)} \int_{\left\{m \leq\left|u_{i, n}\right| \leq m+1\right\}} a_{n}\left(x, t, u_{i, n}, \nabla u_{i, n}\right) \\
& \times \nabla u_{i, n} d x d t,
\end{aligned}
$$

for any $m \geq 1$, and any $\mu>0$. In view (5.37) and 5.38, we can obtain

$$
\begin{aligned}
& \limsup _{n \rightarrow+\infty}\left|\int_{Q_{T}} S_{m}^{\prime \prime}\left(u_{i, n}\right) a_{n}\left(x, t, u_{i, n}, \nabla u_{i, n}\right) \nabla u_{i, n} W_{i, j, \mu}^{n} d x d t\right| \\
& \leq 2 K \limsup _{n \rightarrow+\infty} \int_{\left\{m \leq\left|u_{i, n}\right| \leq m+1\right\}} a_{n}\left(x, t, u_{i, n}, \nabla u_{i, n}\right) \nabla u_{i, n} d x d t,
\end{aligned}
$$

for any $m \geq 1$. Using 5.19 we pass to the limit as $m \rightarrow+\infty$ in 5.50 and we obtain (5.44).

\section{Proof of 5.45):}

For fixed $n \geq 1$ and $n>m+1$, we have

$$
\begin{gathered}
f_{1, n}\left(x, u_{1, n}, u_{2, n}\right) S_{m}^{\prime}\left(u_{1, n}\right) \\
=f_{1}\left(x, T_{m+1}\left(u_{1, n}\right), T_{n}\left(u_{2, n}\right)\right) S_{m}^{\prime}\left(u_{1, n}\right), \\
f_{2, n}\left(x, u_{1, n}, u_{2, n}\right) S_{m}^{\prime}\left(u_{2, n}\right) \\
=f_{2}\left(x, T_{n}\left(u_{1, n}\right), T_{m+1}\left(u_{2, n}\right)\right) S_{m}^{\prime}\left(u_{2, n}\right),
\end{gathered}
$$

In view 4.9, $4.10,5.22$ and Lebesgue's the theorem allow us to get, for

$$
\begin{gathered}
\lim _{n \rightarrow+\infty} \int_{Q_{T}} f_{i, n}\left(x, u_{1, n}, u_{2, n}\right) S_{m}^{\prime}\left(u_{i, n}\right) W_{i, j, \mu}^{n} d x d t \\
=\int_{Q_{T}} f_{i}\left(x, u_{1}, u_{2}\right) S_{m}^{\prime}\left(u_{i}\right) W_{i, j, \mu} d x d t
\end{gathered}
$$

Using 5.35, we follow a similar way we get as $j \rightarrow$ $+\infty$,

$$
\begin{gathered}
\lim _{j \rightarrow+\infty} \int_{Q_{T}} f_{i}\left(x, u_{1}, u_{2}\right) S_{m}^{\prime}\left(u_{i}\right) W_{i, j, \mu} d x d t \\
=\int_{Q_{T}} f_{i}\left(x, u_{1}, u_{2}\right) S_{m}^{\prime}\left(u_{i}\right)\left(T_{K}\left(u_{i}\right)-T_{K}\left(u_{i}\right)_{\mu}\right) d x d t
\end{gathered}
$$

we fixed $m>1$, and using 5.36, we have

$$
\lim _{\mu \rightarrow+\infty} \int_{Q_{T}} f_{i}\left(x, u_{1}, u_{2}\right) S_{m}^{\prime}\left(u_{i}\right)\left(T_{K}\left(u_{i}\right)-T_{K}\left(u_{i}\right)_{\mu}\right) d x d t=0
$$

Then we conclude the proof of 5.45.

Proof of 5.46:

If we pass to the lim-sup when $n, j$ and $\mu$ tends to $+\infty$ and then to the limit as $m$ tends to $+\infty$ in 5.40). We obtain using (5.41)-(5.45), for any $K \geq 0$,

$\lim _{m \rightarrow+\infty} \limsup \limsup _{\mu \rightarrow+\infty} \limsup _{j \rightarrow+\infty} \int_{n \rightarrow+\infty} S_{Q_{T}}^{\prime}\left(u_{i, n}\right) a_{n}\left(x, t, u_{i, n}, \nabla u_{i, n}\right)$

$$
\left(\nabla T_{K}\left(u_{i, n}\right)-\nabla T_{K}\left(v_{i, j}\right)_{\mu}\right) d x d t \leq 0 .
$$

Since

$$
\begin{gathered}
S_{m}^{\prime}\left(u_{i, n}\right) a_{n}\left(x, t, u_{i, n}, \nabla u_{i, n}\right) \nabla T_{K}\left(u_{i, n}\right) \\
=a_{n}\left(x, t, u_{i, n}, \nabla u_{i, n}\right) \nabla T_{K}\left(u_{i, n}\right)
\end{gathered}
$$

for $n>K$ and $K \leq m$. Then, for $K \leq m$,

$$
\begin{aligned}
& \limsup _{n \rightarrow+\infty} \int_{Q_{T}} a_{n}\left(x, t, u_{i, n}, \nabla u_{i, n}\right) \nabla T_{K}\left(u_{i, n}\right) d x d t \\
& \leq \lim _{m \rightarrow+\infty} \limsup _{\mu \rightarrow+\infty} \limsup _{j \rightarrow+\infty} \limsup _{n \rightarrow+\infty} \int_{Q_{T}} S_{m}^{\prime}\left(u_{i, n}\right) \\
& a_{n}\left(x, u_{i, n}, \nabla u_{i, n}\right) \nabla T_{K}\left(v_{i, j}\right)_{\mu} d x d t .
\end{aligned}
$$

Thanks to 5.38, we have in The right hand side of 5.51, for $n>m+1$,

$$
\begin{gathered}
S_{m}^{\prime}\left(u_{i, n}\right) a_{n}\left(x, t, u_{i, n}, \nabla u_{i, n}\right) \\
=S_{m}^{\prime}\left(u_{i, n}\right) a\left(x, t, T_{m+1}\left(u_{i, n}\right), \nabla T_{m+1}\left(u_{i, n}\right)\right) \text { a.e. in } Q_{T} .
\end{gathered}
$$

Using (5.18, and fixing $m \geq 1$, we get

$S_{m}^{\prime}\left(u_{i, n}\right) a_{n}\left(u_{i, n}, \nabla u_{i, n}\right) \rightarrow S_{m}^{\prime}\left(u_{i}\right) X_{i, m+1}$ weakly in $\left(L_{\psi}\left(Q_{T}\right)\right)^{N}$.

when $n \rightarrow+\infty$.

We pass to limit as $j \rightarrow+\infty$ and $\mu \rightarrow+\infty$, and using 5.35)-5.36

$$
\begin{aligned}
& \left.\underset{\mu \rightarrow+\infty}{\limsup } \limsup _{j \rightarrow+\infty} \limsup _{n \rightarrow+\infty} \int_{Q_{T}} S_{m}^{\prime}\left(u_{i, n}\right)\right) a_{n}\left(x, t, u_{i, n}\right. \\
& \left.\left., \nabla u_{i, n}\right)\right) \nabla T_{K}\left(v_{i, j}\right)_{\mu} d x d t \\
& =\int_{Q_{T}} S_{m}^{\prime}\left(u_{i}\right) X_{i, m+1} \nabla T_{K}\left(u_{i}\right) d x d t \\
& =\int_{Q_{T}} X_{i, m+1} \nabla T_{K}\left(u_{i}\right) d x d t
\end{aligned}
$$


where $K \leq m$, since $S_{m}^{\prime}(r)=1$ for $|r| \leq m$.

On the other hand, for $K \leq m$, we have

$$
\begin{aligned}
& a\left(x, t, T_{m+1}\left(u_{i, n}\right), \nabla T_{m+1}\left(u_{i, n}\right)\right) \chi_{\left\{\left|u_{i, n}\right|<K\right\}} \\
& =a\left(x, t, T_{K}\left(u_{i, n}\right), \nabla T_{K}\left(u_{i, n}\right)\right) \chi_{\left\{\left|u_{i, n}\right|<K\right\}},
\end{aligned}
$$

a.e. in $Q_{T}$. Passing to the limit as $n \rightarrow+\infty$, we obtain $X_{i, m+1} \chi_{\left\{\left|u_{i}\right|<K\right\}}=X_{i, K} \chi_{\left\{\left|u_{i}\right|<K\right\}}$ a.e. in $Q_{T}-\left\{\left|u_{i}\right|=K\right\}$ for $K \leq n$.

Then

$$
X_{m+1} \nabla T_{K}\left(u_{i}\right)=X_{K} \nabla T_{K}\left(u_{i}\right) \text { a.e. in } Q_{T} .
$$

Then we obtain (5.46).

Proof of (5.48):

Let $K \geq 0$ be fixed. Using 4.5 we have

$\int_{Q_{T}}\left[a\left(x, t, T_{K}\left(u_{i, n}\right), \nabla T_{K}\left(u_{i, n}\right)\right)-a\left(x, t, T_{K}\left(u_{i, n}\right), \nabla T_{K}\left(u_{i}\right)\right)\right]$ $\left[\nabla T_{K}\left(u_{i, n}\right)-\nabla T_{K}\left(u_{i}\right)\right] d x d t \geq 0$,

In view (1.1) and 5.22), we get

$a\left(x, t, T_{K}\left(u_{i, n}\right), \nabla T_{K}\left(u_{i}\right)\right) \rightarrow a\left(x, t, T_{K}\left(u_{i}\right), \nabla T_{K}\left(u_{i}\right)\right)$ a.e. in $Q_{T}$,

as $n \rightarrow+\infty$, and by 4.2 and Lebesgue's theorem, we obtain

$$
a\left(x, t, T_{K}\left(u_{i, n}\right), \nabla T_{K}\left(u_{i}\right)\right) \rightarrow a\left(x, t, T_{K}\left(u_{i}\right), \nabla T_{K}\left(u_{i}\right)\right)
$$

strongly in $\left(L_{\psi}\left(Q_{T}\right)\right)^{N}$. Using (5.46), (5.22), (5.18) and (5.56), we can pass to the lim-sup as $n \rightarrow+\infty$ in 5.55) to obtain (5.48).

To finish this step, we prove this Lemma:

Lemma 5.2 For $i=1,2$ and fixed $K \geq 0$, we have

$$
X_{i, K}=a\left(x t,, T_{K}\left(u_{i}\right), \nabla T_{K}\left(u_{i}\right)\right) \text { a.e. in } Q \text {. }
$$

Also, as $n \rightarrow+\infty$,

$a\left(x, t, T_{K}\left(u_{i, n}\right), \nabla T_{K}\left(u_{i, n}\right)\right) \nabla T_{K}\left(u_{i, n}\right) \rightarrow a\left(x, t, T_{K}\left(u_{i}\right), D T_{K}\left(u_{i}\right)\right) \nabla T_{K}\left(u_{i}\right)$,

weakly in $L^{1}\left(Q_{T}\right)$.

Proof of (5.57):

It's easy to see that

$a_{n}\left(x, t, T_{K}\left(u_{i, n}\right), \xi\right)=a\left(x, t, T_{K}\left(u_{i, n}\right), \xi\right)=a_{K}\left(x, t, T_{K}\left(u_{i, n}\right), \xi\right)$

a.e. in $Q_{T}$

for any $K \geq 0$, any $n>K$ and any $\xi \in \mathbb{R}^{N}$.

In view of (5.18), (5.48) and (5.56) we obtain

$$
\begin{aligned}
& \lim _{n \rightarrow+\infty} \int_{Q_{T}} a_{K}\left(x, t, T_{K}\left(u_{i, n}\right), \nabla T_{K}\left(u_{i, n}\right)\right) \nabla T_{K}\left(u_{i, n}\right) d x d t \\
& =\int_{Q_{T}} X_{i, K} \nabla T_{K}\left(u_{i}\right) d x d t .
\end{aligned}
$$

Since (1.1), 4.4 and (5.22), imply that the function $a_{K}(x, s, \xi)$ is continuous and bounded with respect to $s$. Then we conclude that 5.57.

Proof of (5.58):

Using (4.5) and (5.48), for any $K \geq 0$ and any $T^{\prime}<T$, we have

$$
\left[a\left(x, t, T_{K}\left(u_{i, n}, \nabla T_{K}\left(u_{i, n}\right)\right)-a\left(x, t, T_{K}\left(u_{i, n}\right), \nabla T_{K}(u)\right)\right]\right.
$$

strongly in $L^{1}\left(Q_{T^{\prime}}\right)$ as $n \rightarrow+\infty$.

On the other hand with (5.22), (5.18), 5.56 and 5.57, we get

$$
\begin{aligned}
& a\left(x, t, T_{K}\left(u_{i, n}\right), \nabla T_{K}\left(u_{i, n}\right)\right) \nabla T_{K}\left(u_{i}\right) \\
& \rightarrow a\left(x, t, T_{K}\left(u_{i}\right), \nabla T_{K}\left(u_{i}\right)\right) \nabla T_{K}\left(u_{i}\right)
\end{aligned}
$$

weakly in $L^{1}\left(Q_{T}\right)$,

$$
\begin{aligned}
& a\left(x, t, T_{K}\left(u_{i, n}\right), \nabla T_{K}\left(u_{i}\right)\right) \nabla T_{K}\left(u_{i, n}\right) \\
& \rightarrow a\left(x, t, T_{K}\left(u_{i}\right), \nabla T_{K}\left(u_{i}\right)\right) \nabla T_{K}\left(u_{i}\right)
\end{aligned}
$$

weakly in $L^{1}\left(Q_{T}\right)$,

$$
\begin{aligned}
& a\left(x, t, T_{K}\left(u_{i, n}\right), \nabla T_{K}\left(u_{i}\right)\right) \nabla T_{K}\left(u_{i}\right) \\
\rightarrow & a\left(x, t, T_{K}\left(u_{i}\right), \nabla T_{K}\left(u_{i}\right)\right) \nabla T_{K}\left(u_{i}\right),
\end{aligned}
$$

strongly in $L^{1}(Q)$, as $n \rightarrow+\infty$.

It's results from 5.60, for any $K \geq 0$ and any $T^{\prime}<T$,

$$
a\left(x, t, T_{K}\left(u_{i, n}\right), \nabla T_{K}\left(u_{i, n}\right)\right) \nabla T_{K}\left(u_{i, n}\right)
$$

weakly in $L^{1}\left(Q_{T^{\prime}}\right)$ as $n \rightarrow+\infty$.then for $T^{\prime}=T$, we have (5.58). Finally we should prove that $u_{i}$ satisfies (4.13).

\section{Step 4:Pass to the limit.}

we first show that $u$ satisfies 4.13

$$
\begin{aligned}
& \int_{\left.m \leq\left|u_{i, n}\right| \leq m+1\right\}} a\left(x, t, u_{i, n}, \nabla u_{i, n}\right) \nabla u_{i, n} d x d t \\
& =\int_{Q_{T}} a_{n}\left(x, t, u_{i, n}, \nabla u_{i, n}\right)\left[\nabla T_{m+1}\left(u_{i, n}\right)-\nabla T_{m}\left(u_{i, n}\right)\right] d x d t \\
& =\int_{Q_{T}} a_{n}\left(x, t, T_{m+1}\left(u_{i, n}\right), \nabla T_{m+1}\left(u_{i, n}\right)\right) \nabla T_{m+1}\left(u_{i, n}\right) d x d t \\
& -\int_{Q_{T}} a_{n}\left(x, t, T_{m}\left(u_{i, n}\right), \nabla T_{m}\left(u_{i, n}\right)\right) \nabla T_{m}\left(u_{i, n}\right) d x d t
\end{aligned}
$$


for $n>m+1$. According to 5.58, one can pass to the limit as $n \rightarrow+\infty$; for fixed $m \geq 0$ to obtain

$$
\begin{aligned}
& \lim _{n \rightarrow+\infty} \int_{\left.m \leq\left|u_{i, n}\right| \leq m+1\right\}} a_{n}\left(x, t, u_{i, n}, \nabla u_{i, n}\right) \nabla u_{i, n} d x d t \\
& =\int_{Q} a\left(x, t, T_{m+1}\left(u_{i}\right), \nabla T_{m+1}\left(u_{i}\right)\right) \nabla T_{m+1}\left(u_{i}\right) d x d t \\
& \quad-\int_{Q} a\left(x, t, T_{m}\left(u_{i}\right), \nabla T_{m}\left(u_{i}\right)\right) \nabla T_{m}\left(u_{i}\right) d x d t \\
& =\int_{\left.m \leq\left|u_{i}\right| \leq m+1\right\}} a\left(x, t, u_{i}, \nabla u_{i}\right) \nabla u_{i} d x d t
\end{aligned}
$$

Pass to limit as $m$ tends to $+\infty$ in 5.62 and using 5.19) show that $u_{i}$ satisfies 4.13.

Now we shown that $u_{i}$ to satisfy 4.14 and 4.15 . Let $S$ be a function in $W^{2, \infty}(\mathbb{R})$ such that $S^{\prime}$ has a compact support. Let $K$ be a positive real number such that supp $S^{\prime} \subset[-K, K]$. the Pointwise multiplication of the approximate equation 1.1 by $S^{\prime}\left(u_{i, n}\right)$ leads to

$$
\begin{aligned}
& \frac{\partial B_{i, S}^{n}\left(u_{i, n}\right)}{\partial t}-\operatorname{div}\left(S^{\prime}\left(u_{i, n}\right) a_{n}\left(x, u_{i, n}, \nabla u_{i, n}\right)\right) \\
& +S^{\prime \prime}\left(u_{i, n}\right) a_{n}\left(x, u_{i, n}, \nabla u_{i, n}\right) \nabla u_{i, n} \\
& -\operatorname{div}\left(S^{\prime}\left(u_{i, n}\right) \Phi_{i, n}\left(x, t, u_{i, n}\right)\right) \\
& +S^{\prime \prime}\left(u_{i, n}\right) \Phi_{i, n}\left(x, t, u_{i, n}\right) \nabla u_{i, n} \\
& =f_{i, n}\left(x, u_{1, n}, u_{1, n}\right) S^{\prime}\left(u_{i, n}\right)
\end{aligned}
$$

in $D^{\prime}\left(Q_{T}\right)$, for $i=1,2$.

Now we pass to the limit in each term of (5.63).

Limit of $\frac{\partial B_{i, S}^{n}\left(u_{i, n}\right)}{\partial t}$ : Since $B_{i, S}^{n}\left(u_{i, n}\right)$ converges to $B_{i, S}\left(u_{i}\right)$ a.e. in $Q_{T}$ and in $L^{\infty}\left(Q_{T}\right)$ weak $\star$ and $S$ is bounded and continuous. Then $\frac{\partial B_{i, S}^{n}\left(u_{i, n}\right)}{\partial t}$ converges to $\frac{\partial b_{i, S}\left(u_{i}\right)}{\partial t}$ in $D^{\prime}\left(Q_{T}\right)$ as $n$ tends to $+\infty$.

Limit of $\operatorname{div}\left(S^{\prime}\left(u_{i, n}\right) a_{n}\left(x, t, u_{i, n}, \nabla u_{i, n}\right)\right)$ :

Since

$\operatorname{supp} S^{\prime} \subset[-K, K]$, for $n>K$, we have

$$
\begin{gathered}
S^{\prime}\left(u_{i, n}\right) a_{n}\left(x, t, u_{i, n}, \nabla u_{i, n}\right) \\
=S^{\prime}\left(u_{i, n}\right) a_{n}\left(x, t, T_{K}\left(u_{i, n}\right), \nabla T_{K}\left(u_{i, n}\right)\right)
\end{gathered}
$$

a.e. in $Q_{T}$. Using the pointwise convergence of $u_{i, n}$ , 5.38, (5.18 and 5.57), imply that

$$
\begin{gathered}
S^{\prime}\left(u_{i, n}\right) a_{n}\left(x, t, T_{K}\left(u_{i, n}\right), \nabla T_{K}\left(u_{i, n}\right)\right) \\
\rightarrow S^{\prime}\left(u_{i}\right) a\left(x, t, T_{K}\left(u_{i}\right), \nabla T_{K}\left(u_{i}\right)\right)
\end{gathered}
$$

weakly in $\left(L_{\psi}\left(Q_{T}\right)\right)^{N}$, for $\sigma\left(\Pi L_{\psi}, \Pi E_{\varphi}\right)$ as $n \rightarrow+\infty$, since $S^{\prime}\left(u_{i}\right)=0$ for $\left|u_{i}\right| \geq K$ a.e. in $Q_{T}$. And

$$
\begin{gathered}
S^{\prime}\left(u_{i}\right) a\left(x, t, T_{K}\left(u_{i}\right), \nabla T_{K}\left(u_{i}\right)\right)=S^{\prime}\left(u_{i}\right) a\left(x, t, u_{i}, \nabla u_{i}\right) \\
\text { a.e. in } Q_{T} .
\end{gathered}
$$

Limit of $S^{\prime \prime}\left(u_{i, n}\right) a_{n}\left(x, t, u_{i, n}, \nabla u_{i, n}\right) \nabla u_{i, n}$. $\operatorname{supp} S^{\prime \prime} \subset[-K, K]$, for $n>K$, we have

$$
S^{\prime \prime}\left(u_{i, n}\right) a_{n}\left(x, t, u_{i, n}, \nabla u_{i, n}\right) \nabla u_{i, n}
$$

$=S^{\prime \prime}\left(u_{i, n}\right) a_{n}\left(x, t, T_{K}\left(u_{i, n}\right), \nabla T_{K}\left(u_{i, n}\right)\right) \nabla T_{K}\left(u_{i, n}\right) \quad$ a.e. in $Q_{T}$.

The pointwise convergence of $S^{\prime \prime}\left(u_{i, n}\right)$ to $S^{\prime \prime}\left(u_{i}\right)$ as $n \rightarrow+\infty$, 5.38 and 5.58 we have

$$
\begin{gathered}
S^{\prime \prime}\left(u_{i, n}\right) a_{n}\left(x, t, u_{i, n}, \nabla u_{i, n}\right) \nabla u_{i, n} \\
\rightarrow S^{\prime \prime}\left(u_{i}\right) a\left(x, t, T_{K}\left(u_{i}\right), \nabla T_{K}\left(u_{i}\right)\right) \nabla T_{K}\left(u_{i}\right)
\end{gathered}
$$

weakly in $L^{1}\left(Q_{T}\right)$, as $n \rightarrow+\infty$, and

$$
\begin{aligned}
& S^{\prime \prime}\left(u_{i}\right) a\left(x, t, T_{K}\left(u_{i}\right), \nabla T_{K}\left(u_{i}\right)\right) \nabla T_{K}\left(u_{i}\right) \\
& =S^{\prime \prime}\left(u_{i}\right) a\left(x, t, u_{i}, \nabla u_{i}\right) \nabla u_{i} \text { a.e.in } Q_{T} .
\end{aligned}
$$

Limit of $S^{\prime}\left(u_{i, n}\right) \Phi_{i, n}\left(x, t, u_{i, n}\right)$ : We have

$$
\begin{gathered}
S^{\prime}\left(u_{i, n}\right) \Phi_{i, n}\left(x, t, u_{i, n}\right) \\
=S^{\prime}\left(u_{i, n}\right) \Phi_{i, n}\left(x, t, T_{K}\left(u_{i, n}\right)\right)
\end{gathered}
$$

a.e.in $Q_{T}$, Since supp $S^{\prime} \subset[-K, K]$.Using 4.5, 5.24 and (5.16), it's easy to see that

$S^{\prime}\left(u_{i, n}\right) \Phi_{i, n}\left(x, t, u_{i, n}\right) \rightarrow S^{\prime}\left(u_{i}\right) \Phi_{i}\left(x, t, T_{K}\left(u_{i}\right)\right)$ weakly for $\sigma\left(\Pi L_{\psi}, \Pi L_{\varphi}\right)$ as $n \rightarrow+\infty$. And $S^{\prime}\left(u_{i}\right) \Phi_{i}\left(x, t, T_{K}\left(u_{i}\right)\right)=$ $S^{\prime}\left(u_{i}\right) \Phi_{i}\left(x, t, u_{i}\right)$ a.e. in $Q_{T}$.

Limit of $S^{\prime \prime}\left(u_{i, n}\right) \Phi_{i, n}\left(x, t, u_{i, n}\right) \nabla u_{i, n}$ : Since $S^{\prime} \in$ $W^{1, \infty}(\mathbb{R})$ with $\operatorname{supp} S^{\prime} \subset[-K, K]$, we have $S^{\prime \prime}\left(u_{i, n}\right) \Phi_{i, n}\left(x, t, u_{i, n}\right) \nabla u_{i, n}=\Phi_{i, n}\left(x, t, T_{K}\left(u_{i, n}\right)\right) \nabla S^{\prime}\left(T_{K}\left(u_{i, n}\right)\right)$ a.e. in $Q_{T}$. The weakly convergence of truncation allows us to prove that

$$
\begin{gathered}
S^{\prime \prime}\left(u_{i, n}\right) \Phi_{i, n}\left(x, t, u_{i, n}\right) \nabla u_{i, n} \rightarrow \Phi_{i}\left(x, t, u_{i}\right) \nabla S^{\prime}\left(u_{i}\right), \\
\text { strongly in } L^{1}\left(Q_{T}\right) .
\end{gathered}
$$

Limit of $f_{i, n}\left(x, u_{1, n}, u_{2, n}\right) S^{\prime}\left(u_{i, n}\right)$ : Using 4.9, (4.10, (5.4) and 5.5), we have

$f_{i, n}\left(x, u_{1, n}, u_{2, n}\right) S^{\prime}\left(u_{i, n}\right) \rightarrow f_{i}\left(x, u_{1}, u_{2}\right) S^{\prime}\left(u_{i}\right)$ strongly in $L^{1}\left(Q_{T}\right)$, as $n \rightarrow+\infty$.

It remains to show that for $\mathrm{i}=1,2 B_{S}\left(x, u_{i}\right)$ satisfies the initial condition 4.15).

To this end, firstly remark that, in view of the definition of $S_{\varphi}^{\prime}$, we have $B_{\varphi}\left(x, u_{i, n}\right)$ is bounded in $L^{\infty}\left(Q_{T}\right)$.

Secondly, by 5.41 we show that $\frac{\partial B_{\varphi}\left(x, u_{i, n}\right)}{\partial t}$ is bounded in $\left.L^{1}\left(Q_{T}\right)+W^{-1, x} L_{\psi}\left(Q_{T}\right)\right)$. As a consequence, an Aubin's type Lemma (see e.g., [11], Corollary 4$)$ implies that $B_{\varphi}\left(x, u_{i, n}\right)$ lies in a compact set of $C^{0}\left([0, T] ; L^{1}(\Omega)\right)$.

It follows that, on one hand, $B_{\varphi}\left(x, u_{i}, n\right)(t=0)$ converges to $B_{\varphi}\left(x, u_{i}\right)(t=0)$ strongly in $L^{1}(\Omega)$. On the order hand, the smoothness of $B_{\varphi}$ imply that $B_{\varphi}\left(x, u_{i, n}\right)(t=0)$ converges to $B_{\varphi}\left(x, u_{i}\right)(t=0)$ strongly in $L^{1}(\Omega)$, we conclude that $B_{\varphi}\left(x, u_{i, n}\right)(t=0)=$ $B_{\varphi}\left(x, u_{i, 0 n}\right)$ converges to $B_{\varphi}\left(x, u_{i}\right)(t=0)$ strongly in $L^{1}(\Omega)$, we obtain $B_{\varphi}\left(x, u_{i}\right)(t=0)=B_{\varphi}\left(x, u_{i, 0}\right)$ a.e. in $\Omega$ and for all $M>0$, now letting $M$ to $+\infty$, we conclude that $b\left(x, u_{i}\right)(t=0)=b\left(x, u_{i, 0}\right)$ a.e. in $\Omega$.

As a conclusion, the proof of Theorem 5.1 is complete. 


\section{References}

1. Adams RA." Sobolev spaces "New York (NY):Academic Press; (1975).

2. R. Di Nardo, F. Féo and O. Guibé. "Existence result for nonlinear parabolic equations with lower order terms".Anal. Appl. Singap. 9, no. 2 (2011), 161-186.

3. Redwane, H. , "Existence of a solution for a class of nonlinear parabolic systems". Electron. J. Qual. Theory Differ. Equ., 24, , 18pp.(2007)

4. Benkirane A., Bennouna J.:" Existence and uniqueness of solution of unilateral problems with $L^{1}$-data in Orlicz spaces". Ital. J. Pure Appl. Math. 16, 87-102 (2004).

5. Kellou M.A., Benkirane A., Douiri S.M.," An inequality of type Poincarée in Musielak spaces and applications to some nonlinear elliptic problems with $L^{1}$-data". Complex Variables and Elliptic Equations 60, pp. 1217-1242, (2015).

6. A. Aberqi , J. Bennouna 2and M. Hammoumi, " Existence
Result for Nonlinear Degenerated Parabolic Systems". Nonlinear Dynamics and Systems Theory, 17 (3) (2017) 217-229.

7. Gossez J.P. :" A strongly nonlinear elliptic problem in Orlicz Sobolev spaces". Proc. Am. Math. Soc. Symp. Pure Math. 45,455-462 (1986).

8. Azroul, E., Redwane, H., M. Rhoudaf, " Existence of a renormalized solution for a class of nonlinear parabolic equations in Orlicz spaces", Port. Math. 66 (1) (2009), 29-63.

9. Aharouch L., Bennouna J.: " Existence and uniqueness of solutions of unilateral problems in Orlicz spaces". Nonlinear Anal. 72, 3553-3565 (2010)

10. Musielak J., :" Modular spaces and Orlicz spaces". Lecture Notes in Math. (1983).

11. Redwane, H. , "Existence of a solution for a class of nonlinear parabolic systems". Electron. J. Qual. Theory Differ. Equ., 24, , 18pp.(2007)

12. Simon, J., " Compact set in the space $L^{p}(0, T, B)$ ". Ann. Mat. Pura, Appl. 146 , pp. 65-96 (1987). 